\title{
EL CONCEPTO DE ACCIÓN Y EL LENGUAJE DE LA IMPUTACIÓN*
}

\author{
Juan Pablo Mañalich R. ** \\ Universidad de Chile
}

RESUMEN. El artículo pretende esclarecer el estatus privilegiado que el concepto de acción tiende a exhibir en el uso adscriptivo del lenguaje. El primer paso está constituido por una reconstrucción crítica de la tesis asociada al así llamado "adscriptivismo", que representa una instancia específica de la falacia del acto de habla. El siguiente paso está constituido por la identificación de las peculiaridades que exhibe el uso adscriptivo del lenguaje, esto es, el así llamado «lenguaje de la imputación». Para esto se sugiere una distinción entre dos aproximaciones posibles, una pragmatista y una ontológica, cuyas implicaciones son examinadas a través de un análisis de la definición kantiana del concepto de imputación. Ello sirve de contexto para la refutación de una interpretación causalista de la noción de agencia. La defensa de una aproximación pragmatista al concepto de imputación lleva a una propuesta de clarificación del estatus lingüístico de las adscripciones de acciones. La tesis consiste en que la fuerza pragmática de un acto de habla adscriptivo se deja analizar como una conjunción de dos fuerzas ilocutivas más básicas, a saber: una asertiva y una declarativa.

Palabras clave: adscriptivismo, concepto de acción, pragmática de la imputación, agencia.

ABSTRACT. The article pretends to clarify the privileged status exhibited by the concept of action in the ascriptive use of language. The first step hereto consists in a critical reconstruction of so called "ascriptivism», which represents a specific token of the speech act fallacy. The next step consists in identifying some special features of the ascriptive use of language, namely the «language of imputation». This leads to exploring a distinction between an ontological and a pragmatist approach, whose implications are examined by reference to KANT's definition of the concept of imputation. This provides a context for a refutation of a causalist interpretation of the notion of agency. The argument for a pragmatist approach to the concept of imputation leads to a clarification of the linguistic status of actions ascriptions. The claim is that the pragmatic force of an ascriptive speech act can be analysed as a conjunction of two more basic ilocutive forces, namely: an assertive and a declarative force.

Keywords: ascriptivism, concept of action, pragmatics of imputation, agency.

* Fecha de recepción: 25 de septiembre de 2012. Fecha de aceptación: 15 de octubre de 2012.

El presente artículo ha podido ser elaborado en el contexto de una estadía de investigación posdoctoral realizada en la Universidad de Bonn, financiada por la Fundación Alexander von Humboldt, y se enmarca en el proyecto FONDECYT núm. 11110274 («La ontología del hecho punible»), del cual el autor es investigador responsable. El autor agradece la colaboración editorial de I. PERIC M. y E. SEREY G., ayudantes ad honorem del Departamento de Ciencias Penales de la Facultad de Derecho de la Universidad de Chile, así como la muy atenta lectura del mismo por parte del profesor G. OvalLE M.

** Doctor en derecho, Universidad de Bonn (2008); licenciado en ciencias jurídicas y sociales, Universidad de Chile (2004); profesor asociado del Departamento de Ciencias Penales de la Facultad de Derecho de la Universidad de Chile. Correo electrónico: jpmanalich@derecho.uchile.cl. 


\section{INTRODUCCIÓN}

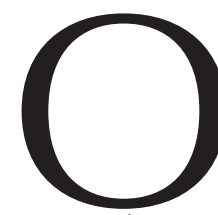

bserva WitTGensteIn en el páragrafo 6.422 del Tractatus Logico-Philosophicus:

El primer pensamiento ante la formulación de una ley ética de la forma «tú debes...» es: ¿y qué si no lo hago? Es claro, empero, que la ética nada tiene que ver con el castigo y la recompensa en el sentido usual. Esto es, la pregunta por las consecuencias asociadas a una acción ha de estar fuera de consideración. A lo menos, estas consecuencias no pueden consistir en eventos. Pues algo correcto tiene que haber, empero, en aquella interpelación. En efecto, tiene que haber un tipo de recompensa ética y de castigo ético, pero éstos tienen que radicar ya en la acción misma.

( $Y$ también es claro que la recompensa tiene que ser algo agradable, y el castigo algo desagradable.)

El pasaje pertenece a aquella sección del Tractatus Logico-Philosophicus que en la literatura secundaria suele presentarse como la «parte mística» de la opera prima de L. WITTGENSTEIN ${ }^{1}$. A pesar de que la sección en cuestión ha llegado a ser evaluada como expresiva de una capital equivocación de parte de su autor — así el lapidario juicio de su discípula, E. ANSCOMBE- ${ }^{2}$, en lo que sigue se intentará mostrar que este preciso pasaje ofrece una clave para entender por qué el concepto de acción ocupa un lugar de inusitado privilegio en el contexto de lo que cabría denominar el «uso adscriptivo del lenguaje», o más desenfadadamente aún: el «lenguaje de la imputación». Ello exige partir revisando la discusión acerca del así llamado «adscriptivismo», la cual puede servir de vía de acceso al problema concerniente a la elucidación de la «gramática profunda» — para mantenernos en la terminología de WITTGENSTEIN— de las adscripciones de acciones.

\section{EL ADSCRIPTIVISMO Y SU CRÍTICA}

Apenas puede sorprender que la discusión acerca del así llamado «adscriptivismo» haya tenido su origen en las proximidades de la teoría del derecho. Pues la relevancia de las categorías jurídicas para el desarrollo de una teoría de los actos de habla —más precisamente: para el hallazgo de la performatividad de las emisiones lingüísticas- fue objeto de atención desde el comienzo ${ }^{3}$. Un temprano artículo de H. L. A. HART ofreció el contexto para la discusión ulterior ${ }^{4}$. HART proponía dos tesis fundamentales: pri-

1 Vid. solamente WigGINS, 2004.

2 Anscombe, 1959: 161 y ss., 171 y ss.

3 Vid. Austin, 1962: 4 (nota 2), 7, 13, 19. Al respecto también CruZ, 1990: 97 y ss., 104 y ss. Cfr. KeLSEN, 1979: 15 y ss., 17: «Un acto —en cuanto se expresa a través de palabras verbalmente formuladas, o escritaspuede él mismo enunciar algo sobre su significado jurídico. En ello se encuentra una peculiaridad del material dado al conocimiento jurídico. Una planta nada puede transmitir sobre sí misma al investigador natural que la determina científicamente. No intenta en forma alguna explicarse a sí misma desde un punto de vista científico natural. Pero un acto de conducta humana puede llevar muy bien consigo una autoatribución de significado jurídico; es decir: contener enunciación sobre lo que significa jurídicamente».

${ }^{4}$ Hart, 1949. Para su recepción y discusión posterior, vid. GEACH, 1960; Pitcher, 1960; Feinberg, 1970: 119 y ss.; SNEDDON, 2006: 19 y ss., 33 y ss., 49 y ss. En el marco de la teoría jurídica, vid. solamente KindHÄUSER, 1980a: 164 y ss.; KORIATH, 1994: 379 y ss.; KuHLEN, 1978: 91 y ss.; MAÑAliCH, 2009: 179 y ss., 
mero, que el sentido de las emisiones lingüísticas por las cuales se dice que alguien ha ejecutado una acción —o más elementalmente: que alguien ha hecho algo- no podría consistir, primariamente al menos, en la descripción de un evento o acontecimiento, sino más bien en una atribución de responsabilidad por el evento en cuestión; y segundo, que el concepto de acción sería un concepto «derrotable» (defeasibel) ${ }^{5}$.

Es importante advertir, por de pronto, la relación de interdependencia en que se encuentran una y otra tesis. Si aquello que uno hace al decir que alguien ha ejecutado una acción efectivamente constituye una atribución de responsabilidad, entonces la adscripción de la acción en cuestión tendría que poder ser «derrotada» en tanto se presenten circunstancias bajo las cuales semejante atribución de responsabilidad deje de ser adecuada. En este sentido, las oraciones relativas-a-acciones (action sentences) exhibirían, según HART, una determinada propiedad distintiva, que él propuso denominar «derrotabilidad». De acuerdo con ello, la derrotabilidad sólo contaría como una propiedad de las oraciones relativas-a-acciones por el hecho de que su sentido o «significado» sería primariamente adscriptivo, y no descriptivo ${ }^{6}$. Con esto, la plausibilidad de la segunda tesis efectivamente depende de la validez de la primera.

Las objeciones dirigidas en contra de la afirmación del carácter necesariamente adscriptivo de las oraciones relativas-a-acciones condujeron a que HART tomase distancia de su temprana tesis ${ }^{7}$. Una primera objeción, formulada por PITCHER, apunta a que sería conceptualmente anómalo entender una acción como posible objeto de (una atribución de) responsabilidad; antes bien, el objeto de responsabilidad estaría constituido por algún evento o estado de cosas que represente el resultado o la consecuencia de lo que alguien ha hecho ${ }^{8}$. Mas PITCHER acepta, al mismo tiempo, la forma de hablar bajo la cual alguien pudiera ser tenido por responsable de haber hecho algo. Que estos dos puntos de vista resulten consistentes entre sí depende, desde luego, de cómo se entienda la relación categorial entre eventos y acciones. A favor de su compatibilidad cabe simplemente observar que, a pesar de que la tesis de que una acción no sería sino un evento de cierta clase es controversial en el marco de la teoría de la acción ${ }^{9}$, hay buenas razones para sostener que la identificación de un evento como la acción de una persona solamente expresa la adopción de un determinado punto de vista, desde el cual ese evento resulta explicable como una instancia de comportamiento intencional de esa persona ${ }^{10}$.

La dificultad a que se enfrenta la tesis de HART queda de manifiesto en la siguiente pregunta formulada por PITCHER: «Si en una conversación digo algo de la forma "él lo hizo”, ¿estoy necesariamente sosteniendo que la persona merece censura, y estoy haciendo esto primariamente?» ${ }^{11}$. Por el momento no es necesario detenerse en la muy

186 y ss.; WÜRFEL, 2012: 68 y ss. En referencia a la discusión en el ámbito del derecho penal angloamericano, DUARTE, 2007.

5 Así la presentación ofrecida por PITCHER, 1960: 226.

${ }^{6}$ Acerca de «la semántica de la derrotabilidad» vid. LouI, 1995: especialmente 22 y ss.

7 Vid. HART, 1968: v (prólogo), haciendo referencia a los artículos de GEACH y PITCHER.

${ }^{8}$ PITCHeR, 1960: passim. En este punto no interesa indagar todavía en los méritos de la distinción concep-

tual entre el resultado y la(s) consecuencia(s) de una acción. Al respecto infra, nota 97.

9 Vid. KINDHÄUSER, 1980a: 124 y ss., 137 y ss., 159 y ss., 163.

10 Vid. DAvidson, 2001: 3 y ss., 43 y ss., 293 y ss. Fundamental asimismo AnSCOMBe, 1963: 83 y ss.

11 Pitcher, 1960: 230. 
decisiva circunstancia de que PITCHER asuma que lo que HART entiende por «responsabilidad», en un sentido bastante «especial», consistiría más bien en un merecimiento de censura o castigo por algo que alguien ha hecho ${ }^{12}$. Pues de eso depende, en efecto, que PITCHER pueda evaluar críticamente la tesis adscriptivista de HART por la vía de reformularla del modo ya sugerido en su pregunta. Lo decisivo aquí es que para PITCHER parezca ser auto-evidente que la respuesta a esa misma pregunta — relativa al significado primariamente adscriptivo de las oraciones relativas-a-acciones - tendría que ser negativa. Esto, a pesar de que PITCHER se muestre dispuesto a aceptar una excepción cuando se trata del uso de expresiones que cabría identificar como «verbos condenatorios», tal como lo serían, por ejemplo, «asesinar» (por oposición a «matar»), «mentir» (por oposición a «decir algo falso») o «hurtar» (por oposición a «hacerse de una cosa ajena») ${ }^{13}$. Pero que el significado de la (emisión de la) oración «A asesinó a B» consista en que A habría de ser tenido por responsable de —o bien sometido a la imposición de una sanción por- haber matado a $\mathrm{B}^{14}$, depende de ciertas circunstancias contextuales, y ya con independencia de si en vez del verbo condenatorio «asesinar» el hablante usara el verbo neutral «matar» ${ }^{15}$. Fuera de este ámbito, en el cual las circunstancias contextuales de la emisión de la respectiva oración serían decisivas para la determinación de su significado, resultaría en todo caso falso decir, según PITCHER, que el sentido primario de las oraciones relativas-a-acciones necesariamente sería el de una atribución de responsabilidad.

HART también menciona la crítica que GEACH dirigiera a su planteamiento como un antecedente determinante para el abandono de su temprana defensa del adscriptivismo. GEACH sostiene que el error lógico que subyace al argumento a favor del adscriptivismo consistiría en una confusión de los conceptos de predicación y aserción, por la vía de ignorar la distinción entre predicar «X» de algo, por un lado, y llamar algo «X», por otro ${ }^{16}$. Para usar el ejemplo ofrecido por GEACH: predicar «es verdad» de una afirmación efectuada por un policía no debería confundirse con afirmar que lo dicho por el policía es verdad. Pues si bien no es posible sostener que lo que ha dicho el policía es verdad sin predicar «es verdad» de lo dicho por el policía, de ello no se sigue, a la inversa, que cada predicación de «es verdad» de lo dicho por el policía conlleve la aserción de que lo que el policía ha dicho es verdad. Resulta obvio, como apunta GEACH, que en el enunciado condicional «si lo que ha dicho el policía es verdad, entonces el motociclista alcanzó las 60 millas por hora», la oración correspondiente a la cláusula antecedente sí expresa la predicación de «es verdad» de lo dicho por el policía, sin que ello implique que el hablante que profiere ese enunciado afirme que lo dicho por el policía es verdad ${ }^{17}$.

La objeción de GEACH sugiere, en otros términos, que la función semántica de la predicación, consistente en la caracterización de uno o más objetos cualesquiera bajo

12 Ibid., 229 y ss.

13 Ibid., 230 y ss. Vid. también FeInBERG, 1970: 120.

${ }^{14}$ Ciertamente, esto no significa que la fuerza adscriptiva de (la emisión de) una oración relativa-a-una acción necesariamente tuviera que consistir en una manifestación de censura o reproche. Antes bien, la adscripción de una acción puede perfectamente resultar expresiva de aprobación o admiración, en tanto se trate, por ejemplo, de la adscripción de una acción meritoria o supererogatoria. Vid. infra, 5.

15 PITCher, 1960: 231.

16 GEACH, 1960: 223.

17 Ibid., 223 y ss. 
un término general, es neutral desde el punto de vista de la específica fuerza pragmática de la (emisión de la) respectiva oración predicativa ${ }^{18}$. En lo que aquí interesa: la circunstancia de que alguien diga «ha hecho X» de alguna persona no alcanza a prejuzgar la clase de acto de habla que el hablante realiza al emitir semejante oración predicativa.

\section{LA FALACIA DEL ACTO DE HABLA}

En pos de establecer con exactitud dónde radica el déficit de la tesis adscriptivista de HART, es imprescindible tomar nota de que aquí se trata más de una pregunta de la filosofía del lenguaje que una de la teoría de la acción: al menos bajo su formulación hartiana, el adscriptivismo constituye una tesis (semántica) acerca del lenguaje en que son usados «términos-de-acción», y no una tesis (metafísica) acerca de la estructura general de la acción ${ }^{19}$. O cabría decir también: la acción cuya estructura es objeto de interés para el adscriptivismo no es la acción de la cual habla quien emite una oración relativa-a-una-acción, sino más bien la acción (lingüística) cuya ejecución tiene lugar a través de la emisión de esa oración.

La hipótesis fundamental del adscriptivismo consiste en la suposición de que existiría algo así como un vocabulario distintivamente adscriptivo, cuya función principal sería la atribución de responsabilidad a aquel de quien se predique la ejecución de una acción. Esto resulta particularmente reconocible en la matizada defensa de la concepción original de HART emprendida por FEINBERG, cuando éste sostiene que la expresión «hacer trampa» (to cheat) ofrecería un ejemplo especialmente claro de cómo la derrotabilidad de una «adscripción de falta» (fault ascription) puede encontrarse ya incrustada en el significado de la expresión verbal a través de la cual se adscribe la falta en cuestión ${ }^{20}$. Según FeINBERG, esto se mostraría en lo «obviamente absurdas» que resultarían expresiones como «hacer trampa inintencionadamente» o «hacer trampa accidentalmente» ${ }^{21}$, de lo cual se seguiría la necesidad de reconocer como perteneciente al significado de «hacer trampa» la disponibilidad de condiciones de excusa cuya verificación dé lugar a la derrota de la adscripción de falta efectuada por el hablante que dice que alguien ha hecho trampa.

El problema se halla en la sugerencia de que la derrotabilidad de una atribución de responsabilidad en virtud de la eventual admisibilidad de condiciones de excusa contaría como un aspecto del significado de una expresión como «hacer trampa». Lo cual supone transformar en una propiedad distintivamente semántica de tal expresión lo que no es más que un rasgo característico de uno de sus principales contextos de uso $^{22}$. Desde luego, con esto no se pretende poner en cuestión que haya expresiones

18 Vid. TugendHAT, 1976: 506 y ss.

19 Vid. SNEDDON, 2006: 8 y ss.

${ }^{20}$ FeINBERG, 1970: 122 y ss.

${ }^{21}$ Para una exhaustiva exploración analítica del concepto de «hacer trampa», vid. GREEN, 2004: especialmente 144 y ss.

22 Acerca de la distinción entre la semántica y la pragmática como dimensiones lingüísticas, BRANDOM, 1994: 180 y ss. Aquí cabría esperar la objeción de que la distinción desconocería el así llamado «giro pragmático» de la filosofía analítica del lenguaje, cuyo lema reza: «significado equivale a uso». Al respecto, vid., por 
lingüísticas cuyo uso entraña una hipótesis de intencionalidad respecto de los acontecimientos que tales expresiones característicamente designan. En atención a la conexión interna que cabe postular entre el carácter intencional de una acción y la explicación de ésta como instancia de comportamiento racional de un agente ${ }^{23}$, no es problemático reconocer la existencia de una clase de expresiones - los así llamados «verbos-deacción»- cuyo uso tiende a generar un contexto adecuado para la pregunta de si alguien ha hecho algo intencionalmente ${ }^{24}$. Lo cual no equivale a que semejante pregunta efectivamente tuviera que entenderse planteada cada vez que un hablante, haciendo uso de algún verbo-de-acción, dice que alguien ha hecho algo ${ }^{25}$. De ahí que DAVIDSON pueda observar, precisamente:

$\mathrm{Si}$, por ejemplo, derramo intencionalmente el contenido de mi tasa, creyendo erróneamente que es té cuando de hecho es café, entonces derramar el café es algo que hago, es una acción mía, a pesar de que lo hago sin intención. Por otro lado, si derramo el café porque tú me haces cosquillas en la mano, no puedo ser llamado el agente. Pero mientras quizá me apresure en ofrecer mis disculpas, no es incorrecto, aun en este caso, decir que yo he derramado el cafée ${ }^{26}$.

Por esto, la constatación de que alguien ha emitido la oración «P ha ejecutado la acción $\phi »$ no ofrece todavía una respuesta a la pregunta acerca de qué fuerza pragmática exhibe la emisión de esa oración en el contexto dado. Lo cual sugiere que la tesis fundamental del adscriptivismo, al menos bajo la formulación que le diera HART, descansa en una instancia de la así llamada «falacia del acto de habla» ${ }^{27}$. Para ilustrar el punto, puede ser útil tener a la vista uno de los ejemplos de semejante falacia.

En la metaética de inspiración analítica es conocida la tesis del así llamado «prescriptivismo universalista», célebremente defendida por HARE. Con arreglo a esta tesis, el «lenguaje de la moral» sería uno de tipo prescriptivo, en el sentido más preciso de que las oraciones que expresan juicios morales tendrían un significado primariamente

ejemplo, HABERMAS, 1988: 52 y ss., 75 y ss. Este lema tiende a ser reconducido a la filosofía tardía de WiTTGENSTEIN, y en particular al $\$ 43$ de las Investigaciones Filosóficas. Pero la atribución simplista de semejante teoría del «significado como uso» a WITTGENSTEIN pasa por alto que en el pasaje de referencia no se afirma lo que usualmente se dice que ahí se afirma. Vid. WitTGENSTEIN, 1984b: $\$ 43$ : «Para una gran clase de casos de utilización de la palabra «significado» — aun cuando no para todos los casos de su utilización一, uno puede explicar esta palabra así: El significado de una palabra es su uso en el lenguaje». Más allá de que el pasaje vuelva explícito que esta fórmula no debería tomarse como una definición (general) del concepto de significado, lo crucial es advertir que, en términos de WitTGENSTEIN, el significado no emerge en el lenguaje, esto es, en el uso de una determinada expresión, sino más bien en la preocupación por explicar en qué consiste el uso de una determinada expresión. En este sentido KRÄMER, 2001: 122 y ss. Aquí es decisivo considerar, sobre todo, el $\$ 560$ de las Investigaciones: «"El significado de la palabra es aquello que la explicación del significado explica”. Es decir: si quieres entender el uso de la palabra "significado", entonces observa qué es lo que uno llama "la explicación del significado"». En detalle al respecto TugENDHAT, 1976: 185 y ss., 199 y ss., según quien esta última observación de WitTGENSTEIN fungiría como el principio básico de la filosofía analítica del lenguaje. A favor de una desmitificación del estatus de la así llamada «filosofía del lenguaje ordinario», y de la posición relativa de WITTGENSTEIN a ese respecto, vid. UsCHANOV, 2002: 27 y ss.

${ }^{23}$ Fundamental DAVIDSON, 2001: 43 y ss., 83 y ss.

${ }^{24}$ La misma pregunta parece hallarse completamente fuera de lugar tratándose del uso de una serie de otros verbos, como por ejemplo el verbo «llover». Vid. DAVIDSON, 2001: 120 y ss.

25 Vid. ya BRENNENSTUHL, 1975: 92 y ss.

26 DAVIDSON, 2001: 45.

27 Vid. SEARLE, 1969: 131, 136 y ss. 
prescriptivo $^{28}$. Uno de los pasos decisivos en la fundamentación de esta tesis se halla en un determinado análisis del predicado «bueno» ${ }^{29}$, que contaría como «palabra de recomendación» general, y cuyas propiedades semánticas serían determinantes para una interpretación prescriptivista de las oraciones que expresan juicios morales, en tanto esas mismas propiedades semánticas también serían reconocibles en términos como «correcto»y «debido» ${ }^{30}$. Uno puede asumir como no controversial la afirmación de que el adjetivo «bueno» es usualmente usado para recomendar un objeto (cualquiera) así caracterizado. Pero la falacia se encuentra, siguiendo aquí a SEARLE ${ }^{31}$, en pretender extraer de ello una determinación del significado de «bueno», que es precisamente lo que pretende HARE: «bueno» tendría un significado primariamente evaluativo o «recomendatorio», y sólo secundariamente un significado descriptivo o informativo ${ }^{32}$.

Se trataría aquí de una falacia, en la medida en que existen muchos contra-ejemplos de oraciones en las cuales el término «bueno» aparece usado literalmente, sin que su emisión lleve necesariamente aparejada la realización (verbal) de alguna recomendación ${ }^{33}$. Así, sería un error concluir, a partir de la observación —en sí misma acertada - de que frecuentemente, «en situaciones normales o estándares», el uso del término «bueno» va aparejado a la realización de un acto ilocutivo del tipo de una recomendación, que entonces el significado de «bueno» se reduciría a su contribución a la realización de actos de habla de ese tipo ${ }^{34}$. Siguiendo a DAVIDSON, esto se sigue simplemente del hecho

de que no hay regla alguna que relacione aquello que las palabras significan, en la interpretación que se intenta obtener de ellas, y aquello que el hablante intenta aseverar, preguntar, poner en duda, ordenar o recomendar, y mucho menos entre estas intenciones y cualquier propósito ulterior ${ }^{35}$.

Lo problemático de la tesis prescriptivista se vuelve más fácil de reconocer si se considera que HARE advierte la diferencia entre el contenido proposicional y la fuerza pragmática (de la emisión) de una oración, aun cuando en términos de una diferencia

28 HARE, 1961: 1 y ss., 11 y ss.; vid. también HARE, 1970. Al respecto, VAN DER PFORDTEN, 1993: 204 y ss., con ulteriores referencias. Para una (temprana) crítica, vid. VON WRIGHT, 1963a: 98 y ss.; también DANIELS, 1970 .

29 HARE, 1961: 79 y ss., 94 y ss., 137 y ss.

30 Ibid., 151 y ss.

31 SEARLE, 1969: 139.

32 HARE, 1961: 111 y ss., 118 y ss.

33 SEARLE, 1969: 138 y ss. Con esto no se pretende desconocer lo problemática que puede resultar la noción misma de que, en relación con el adjetivo «bueno» — o cualquier otro—, cabría diferenciar un significado (o sentido) literal y un significado metafórico, o al menos analógico. Vid. al respecto VON WRIGHT, 1963 b: 13 y ss., quien no descarta, empero, la posibilidad de reconocer instancias de uso parasitario o secundario del término en cuestión.

34 Al respecto, resulta sumamente ilustrativa la comparación, propuesta por VON WRIGHT, 1963 b: 30 y ss., 40 y ss., entre aquellos casos en que el adjetivo «bueno» es usado en sentido «instrumental», típicamente para caracterizar un objeto como bueno para la realización de algún propósito, y aquellos casos en que es utilizado en sentido «técnico», típicamente para caracterizar a un agente como bueno en el desempeño de una actividad o tarea. En los casos del segundo grupo, y siempre que el juicio de «bondad» técnica no sea derivativo o dependiente de un juicio de «bondad» instrumental, el uso del adjetivo «bueno» tendería a exhibir una función laudatoria o congratulatoria, y no recomendatoria.

35 Davidson, 2004: 22. De este modo resulta puesto en cuestión un aspecto crucial de una filosofía del lenguaje como la de SEARLE, en lo cual no es pertinente entrar aquí. Al respecto, vid. MAÑALICH, 2010b: 135 y ss. 
supuestamente expresada en la estructura sintáctica de la respectiva oración, para explicar la diferencia entre órdenes o mandatos, de un lado, y afirmaciones o enunciados, de otro. En efecto, HARE habla del «frástico» para designar «la parte de la oración que es común a ambos modos», y del «néustico» para designar «la parte de la oración que es diferente en el caso de los mandatos y de los enunciados» ${ }^{36}$. De la mano de esta diferenciación, HARE concluye que «si buscamos la diferencia esencial entre enunciados y mandatos, tenemos que atender al néustico, y no al frástico» ${ }^{37}$. En consecuencia, el término «bueno» no podría ser un componente del frástico — esto es, del contenido proposicional- de la oración en cuestión, sino sólo de su néustico, es decir, de aquella dimensión (de la emisión) de una oración en atención a la cual se deja establecer si su fuerza es prescriptiva (o imperativa) o «constatativa» (o asertiva).

Pero a esto se opone el hecho de que el adjetivo «bueno» también pueda ser usado en la emisión de oraciones cuya fuerza es puramente constatativa ${ }^{38}$. Pues según ya se anticipara, la caracterización de un objeto, operada a través de la aplicación de un predicado ${ }^{39}$, jamás alcanza a prejuzgar si a través de la emisión de la respectiva oración predicativa el hablante está efectuando, por ejemplo, una descripción o bien una recomendación de ese mismo objeto ${ }^{40}$. Y mutatis mutandis: del hecho de que un hablante diga que una persona ha ejecutado una acción $\phi$, no podemos inferir que, por esa vía, el hablante necesariamente haya realizado un acto de habla cuya fuerza pragmática sea distintivamente adscriptiva, por oposición a descriptiva, prescriptiva o evaluativa.

\section{HACIA UN CONCEPTO ADSCRIPTIVO DE ACCIÓN}

Hasta aquí se ha ofrecido un argumento dirigido a impugnar la viabilidad de una comprensión adscriptivista de las propiedades semánticas de las así llamadas «oracio-

36 HARE, 1961: 17 y ss., quien con posterioridad, sin embargo, introduciría una ulterior precisión: el «néustico» sólo indicaría la «suscripción» de la correspondiente oración, mientras que la determinación del modo sería la función del respectivo «trópico». Vid. HARE, 1970: 19 y ss.

37 HARE, 1961: 18 y ss.

38 Ello no supone desconocer que un adjetivo como «bueno» exhibe algunas peculiaridades, que se dejan identificar si se lo contrasta, por ejemplo, con un adjetivo como «rojo». Vid. KINDHÄUSER, 1989: 140 y ss. Desde este punto de vista, la particularidad de «bueno» radica en que su significado variará según cuál sea el sustantivo así modificado: mientras que «rojo» significa lo mismo en «X compró un auto rojo» y «X compró un libro rojo», «bueno» difícilmente signifique lo mismo en «X compró un buen auto» $\mathrm{y}$ « $\mathrm{X}$ compró un buen libro». En la (algo problemática) terminología de GEACH, «bueno» cuenta como un «adjetivo atributivo». Vid. GEACH, 1956: 33 y ss. En la terminología de Quine, se trata de un «adjetivo sincategoremático». Vid. QuINE, 1960: 100 y ss., 129 y ss.; también TugENDHAT, 1976: 145, 166 y ss.

39 Por ello es posible definir los predicados como «principios de clasificación». Vid. sólo TugENDHAT, 1976: 40 y ss., 176 y ss. Nótese, empero, que ello supone usar «predicado» algo laxamente, esto es, como equivalente a la expresión «término general». Pues «predicado», estrictamente, designa una categoría sintáctica, y no semántica, de modo tal que, por ejemplo, en una oración del tipo «X es mujer» el predicado está constituido por la expresión «es mujer», y no por el sustantivo «mujer». Por razones de mera simplificación idiomática, empero, cabe favorecer semejante uso laxo del concepto de predicado. Vid. TugENDHAT, 1976: 52, nota 10.

40 Vid. TugENDHAT, 1992: 279: «Es cierto que uno no puede demarcar las expresiones morales por la presencia de determinadas palabras, como "bueno" o "debe"; pero en la semántica no se trata en lo absoluto de la palabra, sino del modo de uso; una y la misma palabra puede tener diversos modos de uso, y oraciones en las cuales no figura la misma palabra pueden, bajo un determinado punto de vista —esto es, aquí: el de la moral- tener el mismo modo de uso». 
nes relativas-a-acciones». Con ello, lo que se ha expuesto hasta aquí es un argumento en contra del adscriptivismo, entendido como una tesis de filosofía del lenguaje, esto es: como una tesis acerca de la «semántica de la acción», y no como una propuesta de teoría de la acción ${ }^{41}$. Esta precisión es pertinente, puesto que por «adscriptivismo» cabría quizá entender una tesis filosófica de otro orden. Precisamente esto subyace a la elaboración de una defensa del adscriptivismo por parte de A. SNEDDON, quien hace explícito, desde el comienzo de su indagación, que el suyo no es un proyecto de semántica filosófica, sino uno de metafísica descriptiva: «la cuestión central concierne a un tipo particular de evento, no a un concepto» ${ }^{42}$. Esto no quiere decir, por supuesto, que SNEDDON renuncie a valerse del concepto de acción como herramienta analítica. Lo interesante, más bien, es que SNEDDON adopte el término «acción» como un término técnico, construido estipulativamente para expresar la satisfacción de las condiciones de las cuales dependería que un evento particular exhiba un determinado estatus, expresado en la caracterización de ese evento como una acción.

En este punto cabe hacer explícito qué significa que el proyecto de indagación metafísica emprendido por SNEDDON sea uno de metafísica descriptiva, por oposición a revisionista ${ }^{43}$. En efecto, se trataría de establecer, en atención a nuestra práctica lingüística cotidiana, cuáles son las condiciones de las cuales depende, que un evento cualquiera cuente como una acción ${ }^{44}$. De ahí que lo que interese a SNEDDON no sea lo que enseñe el uso cotidiano u ordinario del término «acción», sino cuál es la taxonomía de la acción susceptible de ser identificada en esa práctica lingüística. Así, SNEDDON aparece siguiendo al pie de la letra el consejo que, en su evaluación crítica del seminal artículo de HART, MACKIE dirigiera a quienes se inclinan por cultivar la así llamada «filosofía del lenguaje ordinario», a saber: «trabajar a través del lenguaje hacia los hechos» ${ }^{45}$. Todo lo cual está en perfecto orden, siempre que uno no olvide que la distinción entre el lenguaje y los hechos parece ser, en último término, impracticable. Si el mundo - a diferencia del universo- «es la totalidad de los hechos y no de las cosas» ${ }^{46}$, y un hecho no es sino una proposición verdadera ${ }^{47}$, entonces el mundo cuenta como un espacio lingüísticamente estructurado, esto es, como un espacio de significación ${ }^{48}$. De ahí que WitTGENSTEIN pueda decir:

Uno no tiene que preguntar qué son las representaciones, o qué acontece cuando uno se representa algo, sino: cómo es usada la palabra «representación». Pero eso no significa que yo solamente quiera hablar acerca de palabras. Pues en la medida en que en mi pre-

41 Para esta distinción, vid. ya BREnNENSTUHL, 1975: 191 y ss.

42 SNEDDON, 2006: 10.

43 Vid. STRAWSOn, 1964: 9 y ss.

44 SNEDDON, 2006: 8 y ss.

45 MACKIE, 1985: 42.

46 Vid. WitTgenstein, 1984a: $\$ 5.6$.

47 Fundamental para la correspondiente distinción entre eventos y hechos, VENDLER, 1967: 122 y ss., 142 y ss.; DAVIDSON, 2001: 163 y ss.

48 Para la correspondiente comprensión de la relación (interna) entre lenguaje y mundo en el contexto del Tractatus y la obra posterior de WiTtGenstein, vid. MCGINN, 2001: especialmente 28 y ss., 32 y ss. Ciertamente, aquél dista de ser el único concepto filosóficamente viable de mundo. Para una contraposición, vid. VENDLER, 1967: 142 y ss., 145 y ss., quien sostiene que los objetos serían parte del mundo, así como los eventos tendrían lugar en el mundo, no así los hechos, que más bien serían acerca de objetos y eventos, esto es, acerca del mundo. Esto muestra, notablemente, el notable paralelismo entre uno y otro punto de vista, que se distinguen, precisamente, por articular conceptos inversos de mundo. 
gunta se habla de la palabra «representación», entonces en la pregunta también se está hablando de la esencia de la representación ${ }^{49}$.

Este pasaje ejemplifica la estrategia filosófica que QUINE denominara «ascenso semántico»: en vez de examinar (directamente) qué es $\mathrm{X}$, examinamos la manera en que usamos (el término) «X» ${ }^{50}$. El término que aquí interesa es «acción». Pero a este respecto, SNEDDON observa que para referirnos a lo que alguien ha hecho no solemos utilizar precisamente este término. Lo usual, más bien, es que nos valgamos de simples «términos-de-acción»; y más específicamente, algún verbo-de-acción ${ }^{51}$. De ahí que, según SNEDDON, el objetivo consista en identificar los criterios, reconocibles en nuestra práctica lingüística cotidiana, que determinan si un evento cualquiera cuenta como la acción de una persona, con total independencia de si en esa práctica lingüística aparece el término «acción» ${ }^{52}$. Su apuesta es que, en atención al conjunto de criterios que permanecerían implícitos en nuestra práctica lingüística, el estatus de un evento particular como constitutivo de una acción habría de recibir la siguiente definición: «la posibilidad de atribuir responsabilidad por un evento es una condición-de-tipo necesaria para que ese evento cuente como una acción» ${ }^{53}$. Que se trate aquí de una condición-de-tipo necesaria, por oposición a una condición-de-instancia necesaria, significa que se trata de una condición necesaria para que un evento cualquiera ejemplifique el tipo de evento designado por el término «acción» ${ }^{54}$. Y la condición consiste en que el evento en cuestión pueda fungir como eventual objeto de una atribución de responsabilidad a una o más personas.

Así, el proyecto de SNEDDON consiste en la elaboración y la defensa de un concepto adscriptivo de acción. Pero SNEDDON efectivamente se abstiene de incurrir en la falacia del acto de habla que aqueja a la formulación hartiana del adscriptivismo. Pues su tesis no es que cada vez que un hablante dice que alguna persona ha hecho algo, ese hablante esté realizando, ceteris paribus, un acto de habla que pudiésemos identificar con una atribución (indiciaria o definitiva) de responsabilidad. Antes bien, SNEDDON pretende identificar los criterios que definen lo que cuenta como adscribir una acción —entendida como un evento por el cual alguien puede llegar a ser hecho responsable- en nuestra práctica lingüística cotidiana, en su referencia a lo que hacemos o dejamos de hacer, pero no porque tal práctica lingüística exhiba un compromiso específico con aquello que, por vía de abstracción, podemos tematizar como un juego de lenguaje propiamente «adscriptivo», lo cual significa: potencialmente atributivo-de-responsabilidad. Adscribir una acción a alguien, en este sentido, efectivamente equivale a realizar un acto de habla; pero el carácter específicamente «adscriptivo» de semejante acto de habla no es dependiente del uso de un determinado vocabulario o de algún repertorio más o menos distintivo de «oraciones-relativas-a-acciones» ${ }^{55}$. Pues para saber qué es lo

\footnotetext{
49 WitTGenstein, 1984b: $\$ 370$.

50 Quine, 1960: 270 y ss.

51 Al respecto, vid. ya Austin, 1970: 175 y ss., 178 y ss.; DANTO, 1973: 7 y ss.; BrenNENSTUHL, 1975: 18 y ss.

52 SNEDDON, 2006: 10 y ss.

53 Ibid., 19.

54 Ibid., 13 y ss.

55 Nótese que, en estos términos, el carácter «adscriptivo» (= atributivo-de-responsabilidad) de la adscripción de una acción no está asociado al hecho de tratarse de una adscripción, sino al hecho de tratarse de la adscripción de una acción. À la SNEDDON, en la expresión «adscripción de una acción» el término «adscrip-
} 
que alguien ha hecho —esto es: para saber qué clase de acto de habla ha realizado-al decir lo que ha dicho, no basta con saber qué es lo que ha dicho.

\section{EL LENGUAJE DE LA IMPUTACIÓN}

La precisión anterior puede contribuir a dilucidar lo que está en juego en la interpretación de un evento cualquiera como la acción de una persona. Pues si SNEDDON tiene razón, la adscripción de una acción a alguien tendría que identificarse con la realización de una «jugada» - por parte de un hablante- en el marco de un determinado «juego de lenguaje», el cual no consiste sino en un determinado modo de uso del lenguaje, que cabría denominar «adscriptivo». Y es semejante uso adscriptivo del lenguaje lo que admite identificarse, por vía de hipóstasis, como el «lenguaje de la imputación» ${ }^{56}$. Se trata de una hipóstasis, porque en rigor no hay tal cosa como el lenguaje de la imputación ${ }^{57}$. De lo que se trata, más bien, es de clarificar qué es lo que hacemos lingüisticamente cuando atribuimos responsabilidad a una persona por algo que ha hecho (o dejado de hacer) ${ }^{58}$. La cuestión que aquí interesa se refiere a las razones por las cuales el concepto de acción podría ocupar un lugar privilegiado en el contexto del lenguaje de la imputación, tal como lo sugiere SNEDDON al afirmar que «[a]dscribir una acción a una persona es, necesariamente, describir un evento como una acción y plantear la posibilidad de atribuir responsabilidad por esa acción a esa persona» ${ }^{59}$.

Cabe partir reparando aquí en que el término «imputación» exhibe un alto grado de parentesco semántico con términos cuyo uso más reconocible podemos reconducir al dominio de la contabilidad. Pues «imputar», tal como plásticamente lo sugiere su equivalente alemán (zu-rechnen), en todo caso significa poner algo en la cuenta de alguien ${ }^{60}$. En la formulación del jurista («hegeliano») BERNER: «Imputar quiere decir,

ción» no significa más que «alocación». Ello puede resultar idiomáticamente incómodo, dado que el adjetivo «adscriptivo» está construido sobre la base del verbo «adscribir», cuya sustantivación lleva, precisamente, a «adscripción». Puesto que — a consecuencia del impacto del seminal artículo de HART- en la literatura filosófica se encuentra ampliamente extendido el uso de «adscriptivo» como equivalente a «atributivo-deresponsabilidad», aquí se optará por no innovar al respecto.

56 Fundamental al respecto HrUSCHKA, 1976: 1 y ss., 13 y ss.; HRUSCHKA, 1986; HRUSCHKA, 2004, con precisiones etimológicas; HRUSCHKA, 1988: 424 y ss. Vid. también KINDHÄUSER, 1984: 5 y ss.; MEIXNER, 1994; MAÑALICH, 2009: 75 y ss.

57 Es más: con DAVIDSON cabría decir que no hay tal cosa como el lenguaje («a secas»). Vid. DAVIDSON, 2005: 89 y ss., 107. Al respecto MAÑALICH, 2010b: 144 y ss.

58 Esto no supone entender que el objeto de una posible atribución de responsabilidad a una persona siempre tuviera que estar circunscrito a la realización o no-realización de (la descripción de) una determinada acción. Antes bien, ésta no es sino una de las posibles estructuras que puede exhibir una atribución de responsabilidad personal, que en ningún caso necesita ser tomada como la fundamental. Vid. DAN-COHEN, 2002: 199 y ss., 202 y ss., 209 y ss., quien da cuenta de la posición dependiente del paradigma de atribución de responsabilidad por (la ejecución u omisión de) una «acción voluntaria» frente a los paradigmas (progresivamente más primarios) de la atribución de responsabilidad por el (propio) carácter y de la atribución de responsabilidad por «el sí-mismo» (the self). Acerca de la relación interna en que se encuentran los conceptos de responsabilidad, autodeterminación y auto-constitución, vid. MAÑALICH, 2010a: 56 y ss., con ulteriores referencias.

59 SNEDDON, 2006: 28.

60 Vid. HruschKa, 1976: 13 y ss.; HruschKa, 2004: 17 y ss.; Cacciatore, 2004. Vid. también SÁnCHEZOsTIZ, 2008: 63 y ss., 69, con nota 33. Sólo para evitar posibles confusiones, cabe reparar en que se conocen usos más restringidos del concepto de imputación —o lo que es lo mismo: conceptos más restringidos de imputación-, tal como el que hace suyo ROBINSON, 1984, quien por «imputación» entiende toda operación 
como podemos decir provisionalmente: registrar algo objetivo en la cuenta de un sujeto» ${ }^{61}$. Pero ello no basta todavía para dar cuenta de la relación en que se encuentran el concepto de imputación y el concepto de acción, construido este último como un concepto propiamente adscriptivo.

La estipulación de un concepto adscriptivo de acción à la SNEDDON vuelve idiomáticamente impropio hablar de «la imputación de una acción», en la medida en que, en estos términos, semejante expresión constituye un pleonasmo. Pues adscribir una acción a una persona equivale, en estos mismos términos, a plantear la posibilidad de atribuir responsabilidad a esa persona por un determinado evento. Luego, si «imputar» significa poner algo en la cuenta de alguien, es redundante hablar de «la imputación de una acción»: la caracterización de un evento como la acción de una persona entraña ya lo que cabría llamar una «hipótesis de imputabilidad». (Nótese que lo mismo no es predicable de la expresión «la adscripción de una acción». Pues por «adscripción», en este contexto, no cabe entender más que una «alocación», sin que esta última noción sugiera una referencia a «cuenta normativa» alguna ${ }^{62}$ ). Así se deja reformular, por lo demás, la primera de las objeciones que PITCHER dirigiera a la versión hartiana de la tesis adscriptivista ${ }^{63}$.

Pero en este punto se vuelve imprescindible clarificar la metáfora contable, según la cual imputar algo a alguien consiste, en los términos ya reseñados, en poner algo en la cuenta de alguien ${ }^{64}$. Las mejores herramientas conceptuales disponibles para ello pueden ser tomadas prestadas de BRANDOM, a propósito de su descripción de nuestras prácticas de atribución de compromisos doxásticos y compromisos prácticos —es decir, de creencias e intenciones- como prácticas de «registro-en-cuenta deóntico» (deontic scorekeeping) ${ }^{65}$. En la medida en que lo distintivo de una acción se halla en el hecho de que ante su ejecución es siempre potencialmente pertinente pedir u ofrecer

de atribución de responsabilidad fundada en el reconocimiento de alguna excepción justificada o legítima frente a la falta de satisfacción de algún presupuesto paradigmático de una atribución de responsabilidad. En tal medida, esta noción (restringida) de imputación se corresponde con la noción (estricta) de imputación extraordinaria. Para la distinción entre los conceptos de imputación ordinaria e imputación extraordinaria, vid. HRUSCHKA, 1988: 274 y ss., 313 y ss.; MAÑALICH, 2009: 67 y ss.; SÁNCHEZ-Ostiz, 2008: 13 y ss., 32 y ss., con ulteriores referencias.

61 BERNER, 1843: 39. Una documentada revisión de la evolución histórica del concepto de imputación en la tradición de la filosofía práctica y jurídica — cuyo primer hito es identificado con Aristóteles- se encuentra en HARDWIG, 1957: 11 y ss. En particular respecto de la concepción hegeliana de la imputación, así como de su recepción en el discurso de la dogmática jurídico-penal alemana, vid. vON BUBNOFF, 1966: 36 y ss., 52 y ss.; SÁnCHEZ-OstiZ, 2008: 275 y ss. De importancia al respecto ya RADBRUCH, 1967: 85 y ss.

62 Vid. supra, nota 55.

${ }^{63}$ Vid. supra, en particular la sección del texto principal acompañada por las notas 8-10. Desde luego, uno podría refinar todavía más la terminología, desde ya en atención a la posibilidad de atribuir responsabilidad por la omisión de una determinada acción. Esto es pasado por alto por MEIXNER, 1994: 480 y ss., 500 y ss., quien se inclina por entender que una omisión también contaría como algo que alguien bace, esto es, como un becho (Tat); acerca de las omisiones como «acciones de segundo orden», vid. también BRENNENSTUHL, 1975: 262 y ss.; KINDHÄUSER, 1980a: 175 y ss. El problema está en que —en contra de lo sugerido por DANTO, 1973: 165 y ss., 171, quien afirma la posibilidad ontológica de un «evento negativo»— no hay evento alguno que se corresponda con la omisión de una acción. Vid. VOGEL, 1993: 112 y ss.; MOORE, 1993: 28 y ss.; MOORE, 1997: 262 y ss. Lo importante aquí es advertir que, si se favorece una terminología bajo la cual lo que haya de ser imputable a una persona sea la realización o no-realización de la descripción de una acción —en esta línea BIRNBACHER, 1995: 32 y ss.—, el término «acción» ya no estará siendo usado adscriptivamente.

${ }^{64}$ En este sentido ya FeINBERG, 1970: 124 y ss.

65 BRANDOM, 1994: 180 y ss., 229 y ss. 
razones, la ejecución de una acción es expresiva de la adopción —en primera persona- de un determinado compromiso práctico por parte del agente, lo cual se sigue de que la ejecución de una acción sirve de título o autorización para la atribución —en tercera persona- de un determinado compromiso práctico al agente ${ }^{66}$. Ello hace posible identificar el «lenguaje de la imputación» con un modo de uso del lenguaje que se caracteriza —en la terminología de BRANDOM - por hacer explícitos los compromisos prácticos susceptibles de ser atribuidos a un agente cualquiera, en la forma de una práctica de registro discursivo de los cargos y abonos que van constituyendo su respectivo «estado de cuenta».

Qué haya que entender por «cargo» y «abono» en este contexto, dependerá de cuál pueda ser el objetivo perseguido a través del correspondiente registro en cuenta. Esto se deja ilustrar a través de un análisis de la terminología favorecida por la doctrina de la imputatio de la tradición del derecho natural racional, que llegó a elaborar una reconstrucción general de la imputación como un juicio práctico de dos niveles ${ }^{67}$. En el primer nivel, se trata de la constitución de un suceso como el hecho de una persona, en el sentido de una imputatio facti; en el segundo nivel, en cambio, de la imputación de ese hecho - ya constituido como tal por vía de una imputatio facti- como un hecho meritorio o demeritorio, en el sentido de una imputatio iuris. Lo crucial es que esto último presupone ya un juzgamiento del hecho bajo un determinado estándar de comportamiento, en el sentido de una applicatio legis ad factum. Pues de cuál sea el estatus normativo del hecho dependerá que éste pueda resultar imputable —en el nivel de la imputatio iuris - a título de mérito o demérito a su autor, esto es: en el sentido del abono de un «crédito» o del cargo de una «deuda», respectivamente, en la cuenta (normativa) del agente ${ }^{68}$. Y es recién este registro de un crédito o una deuda en la cuenta del agente lo que podría legitimar una reacción favorable o desfavorable a su respecto, como consecuencia asociada a la imputación, en la forma del otorgamiento de un premio o de la imposición de un castigo, según corresponda.

Esta última distinción entre la operación del registro de una deuda y la habilitación a la consiguiente imposición de una sanción, tratándose de la imputatio iuris del quebrantamiento de un estándar de comportamiento, encuentra un paralelismo directo en el análisis de los estadios en que podría descomponerse el proceso de reacción discursiva ante una performance defectuosa o incorrecta de algún agente, ofrecido por FEINBERG. Según éste, esos tres estadios serían: 1) la constatación de la performance defectuosa en tanto tal; 2) la adscripción - esencialmente derrotable- de esa performan$c e$, en la forma de un cargo en la cuenta del agente, y 3) la puesta-en-uso del registro así modificado, para hacer operativa alguna consecuencia susceptible de ser asociada a la adscripción de la performance en cuestión, entre las cuales ciertamente podría figurar

66 Ibid., 161 y ss., 196 y ss.

67 Fundamental HruschKa, 1976: 34 y ss.; HruschKa, 2005: 30 y ss., 34, 79 y ss.; SÁnCHEZ-OsTiz, 2008: 25 y ss. Vid. también STÜBINGER, 2011: 158 y ss. La recuperación de la distinción de los dos niveles de la imputación ya se encuentra en LARENZ, 1927: 60 y ss., 69 y ss., quien enfatizaba las desventajas de su disolución por vía de su sustitución a través de un juicio total y global de imputación, favorecida por la escuela de «los hegelianos». Sobre los «niveles de la imputación» —aunque en un sentido manifiestamente divergente- reconocibles en la filosofía del derecho de Hegel, vid. SEELman, 2004.

68 Vid. SÁNCHEZ-Ostiz, 2008: 103 y ss.; también STÜBINGER, 2011: 160 y ss. No deja de ser notable que el término alemán correspondiente a «deuda» — Schuld — también sea el correspondiente a «culpa». 
una objetivación o materialización del reproche implicado en dicha adscripción, en la forma de la imposición de una sanción (más o menos) institucionalizada ${ }^{69}$. Esto último es crucial, en la medida en que ofrece, por contraste, una clave para identificar el quid de la observación de WiTTGENSTEIN acerca del premio y el castigo en sentido ético. Pues en un sentido puramente ético à la WITTGENSTEIN ${ }^{70}$, tendría que ser posible reconocer ya un «castigo» en la sola adscripción de una performance defectuosa, esto es, en su solo registro en la cuenta del agente, con prescindencia de cualquier consecuencia susceptible de ser asociada a esa misma adscripción.

Sobre ello habrá que volver más adelante. Por el momento, cabe constatar que, en los términos del precedente análisis de la metáfora contable, la caracterización de la adscripción de una acción como derrotable se deja explicar sin más en atención a la especificidad de la práctica de registro-en-cuenta. Pues para ponerlo en terminología forense, y circunscribiendo nuevamente el problema a la eventual atribución de responsabilidad a modo de reproche: la posibilidad de que se vea derrotada la adscripción de la performance en cuestión no es sino la posibilidad de que decaigan las razones sobre las cuales se apoya el correspondiente cargo, o bien de que se impongan razones que hayan de servir como descargo. Lo cual hace fácil reconocer la variable procedimental que se esconde tras la noción -indispensable para una reconstrucción dialógica del discurso de aplicación del derecho penal- de eximente de responsabilidad, en el sentido preciso de que una eximente cuenta como una razón de descargo, susceptible de ser opuesta a las razones en las cuales se apoya el cargo respectivo ${ }^{71}$. Y es en atención a la específica ratio del respectivo descargo que se deja entender la tradicional distinción entre eximentes constitutivas de condiciones de justificación y eximentes constitutivas de condiciones de excusa: una condición de justificación revierte el estatus (normativamente) peyorativo del objeto de la eventual imputación, mientras que una condición de excusa compromete la satisfacción de alguno de los criterios de cuya satisfacción conjunta depende esa eventual imputación ${ }^{72}$.

\section{IMPUTACIÓN, CAUSALIDAD Y AGENCIA}

La comprensión de la imputación como un juicio a través del cual algo es puesto en la cuenta normativa - moral o jurídica - de un agente se corresponde con una aproximación pragmatista al concepto de imputación, en la medida en que la posibilidad misma de que algo resulte imputable a alguien —esto es, de la correspondiente

69 FeInBerg, 1970: 127 y ss.

70 Acerca de la noción de lo ético en el contexto del Tractatus, también desde el punto de vista de su mayor o menor continuidad en la posterior obra filosófica de WITTGENSTEIN, vid. RHEES, 1965; WALKER, 1968; KELLY, 1995; SCHULTE, 1989: 96 y ss.

71 Vid. al respecto la observación de MACKIE, 1985: 40 y ss., en cuanto al estatus de las eximentes o «defensas» (defences) como razones que obstan a una atribución de responsabilidad por una performance defectuosa; al respecto también BRENNENSTUHL, 1975: 55 y ss. Fundamental para el esbozo de un modelo dialógico de la imputación jurídico-penal, NEUMANN, 1985: 269 y ss., 276 y ss.

72 Una célebre formulación de esta distinción se encuentra en AUSTIN, 1970: 176: «In the one defence, briefly, we accept responsibility but deny that it was bad: in the other, we admit that it was bad but don't take full, or even any, responsibility». Fundamental también GÜNTHER, 2005: 203 y ss. En lo que aquí interesa, la distinción descansa sobre una distinción más básica entre el objeto y los criterios (o bases) de la imputación. Para un esbozo programático, vid. MAÑALICH, 2009: 23 y ss.; MAÑALICH, 2010c. 
relación de imputación - es dependiente, bajo esta comprensión, de una praxis que confiere sentido a ese juicio adscriptivo en tanto tal. Ello contrasta con la posibilidad de una aproximación ontológica al concepto de imputación, que admitiría ser caracterizada por la preocupación de determinar el sustrato óntico de una posible relación de imputación ${ }^{73}$.

Lo usual es que una aproximación ontológica identifique la causalidad como la categoría que tendría que proveer el sustrato óntico a una posible relación de imputación: para que $\mathrm{X}$ sea imputable a $\mathrm{Y}, \mathrm{Y}$ ha de haber causado $\mathrm{X}^{74}$. Por supuesto, ello no implica que toda relación de imputación tuviera que ser reducible a una correspondiente relación de causalidad; se trata, más bien, de que la existencia de tal relación de causalidad contaría como condición necesaria de la existencia de la correspondiente relación de imputación. Lo importante aquí es notar que si una relación de imputación se entiende construida sobre una correspondiente relación de causalidad, ello parece llevar a la conclusión de que tal relación de imputación exhibiría una estructura diádica —esto es, se constituiría como una relación de dos términos (o relata)—, cuyo establecimiento parecería agotarse en la constatación de que X es imputable a Y.

Una aproximación pragmatista, en cambio, lleva a poner el énfasis en que el establecimiento de una relación de imputación sólo puede tener lugar a través de un juicio por el cual $\mathrm{X}$ es puesto en la cuenta de $\mathrm{Y}^{75}$. Esto no significa que tal imputación quede inmunizada frente a la posibilidad de error. Antes bien, una comprensión de la imputación al modo de un juicio adscriptivo efectuado por alguien es enteramente compatible con el reconocimiento de la posibilidad de que el respectivo juicio de imputación también pueda contar, a su vez, como una performance defectuosa o incorrecta. Precisamente esto es lo que aparece en juego cuando se tematizan reglas que enuncian las condiciones de las cuales depende que la correspondiente atribución de responsabilidad se encuentre justificada, o en la terminología de BRANDOM: las condiciones de las cuales depende que quien efectúa el registro en la cuenta de otro disponga de un título legitimante (entitlement) para ello ${ }^{76}$. Esto sugiere, a su vez, que una aproximación pragmatista lleva a la conclusión de que la respectiva relación de imputación ha de exhibir una estructura triádica. Pues los términos de una relación de una imputación ya no quedan reducidos a su objeto (= lo que se imputa) y su sujetivo pasivo (= a quien se imputa), sino que como tercer término aparece su sujeto activo (= quien imputa): $\mathrm{X}$ es imputable a $\mathrm{Y}$ por parte de $\mathrm{Z}^{77}$. Conceptualmente al menos, no hay razón alguna para asumir que la imputabilidad de $\mathrm{X}$ a $\mathrm{Y}$ tuviera que entenderse construida sobre la base de una relación de causalidad entre $\mathrm{X}$ e $\mathrm{Y}$, en tanto esta relación de imputación

73 La distinción así propuesta se corresponde, grosso modo, con la distinción entre una «interpretación pragmática» y una «interpretación metafísica» de lo que cuenta como ser responsable de algo. Vid. SNEDDON, 2006: 79 y ss., 87. Para una aplicación de la misma distinción al problema de la determinación del estatus de persona, vid. LANCE y WHITE, 2007.

${ }^{74}$ MeIXNeR, 1994: 481 y ss.; vid. también JoERDEN, 1988: 16 y ss.

75 Vid. solamente KINDHÄUSER, 1982: 493 y ss.; KINDHÄUSER, 1984: 5 y ss.

76 Vid. BRANDOM, 1994: 182 y ss., 184; con matices también SNEDDON, 2006: 79 y ss.; acerca del estatus de las «reglas de imputación», vid. HRUSCHKA, 1986: 680 y ss., 682 y ss.; MAÑALICH, 2009: 36 y ss., 46 y ss.; MAÑALICH, 2010c: 178 y ss. De importancia al respecto el análisis de WÜRFEL, 2012: 137 y ss., 157 y ss.

77 La cuestión del «sujeto activo» de la imputación es infrecuentemente considerada en la discusión más reciente. Para una muestra aislada, y en todo caso circunscrita al problema de la así llamada «imputación objetiva», vid. ZACZYK, 2007. 
se entienda constituida por la vía de un juicio práctico (susceptible de ser) efectuado por $Z^{78}$.

Notablemente, una conjunción de las dos aproximaciones hasta aquí contrapuestas parece encontrarse en la célebre definición ofrecida por KANT, según quien por «imputación» habría que entender, «en su significado moral»,

el juicio a través del cual alguien es considerado como el autor (causa libera) de una acción, que entonces se denomina hecho (factum) y queda sometida a las leyes; el cual, si al mismo tiempo trae consigo las consecuencias jurídicas del hecho, sería una imputación con fuerza jurídica (imputatio judiciaria s. valida), en caso contrario solamente una imputación enjuiciadora (imputatio disjudicatoria). Aquella persona (física o moral) que tiene autorización para imputar con fuerza jurídica se llama juez o también tribunal (judex s. forum $)^{79}$.

El pasaje vuelve indubitable el compromiso de KANT con una aproximación pragmatista al concepto de imputación. Ese compromiso se expresa, desde ya, en la identificación de la imputación con un juicio, cuyo inequívoco sentido práctico se manifiesta en la circunstancia de que el «hecho» (Tat) constituido por vía de imputación pueda quedar sometido, en tal medida, a evaluación con arreglo a normas o «leyes (prácticas)» ${ }^{80}$. Y es asimismo significativo que, al menos en la especificación del concepto de imputación con validez jurídica, KANT incluya una referencia a lo que más arriba se identificara como el sujeto activo de la imputación.

Pero al mismo tiempo, en la definición kantiana también es reconocible un cierto compromiso con una aproximación ontológica, al menos en lo concerniente a cómo habría que entender, más precisamente, la infraestructura de la relación entre el agente y aquello que se le imputa como su hecho (u «obra») ${ }^{81}$. Pues según KANT, el agente ha de ser visto como la «causa libre» de la respectiva acción. Precisamente sobre esta base se ha intentado, en el marco de la reconstrucción teórica de los presupuestos de la imputación jurídico-penal, ofrecer un sustento para la tradicional «doctrina de la prohibición de regreso», según la cual la plena imputabilidad de un hecho (Tat) a una persona bloquearía toda eventual conexión causal entre el hecho y cualquier conjunto de circunstancias preexistentes al hito representado por la intervención libre y voluntaria del agente, o más precisamente: por su resolución de voluntad libremente motivada ${ }^{82}$. En estos términos, la causa libera de una acción tendría que ser entendida como una causa (a su vez) «libre de causa» ${ }^{83}$.

78 Análogamente SNEDDON, 2006: 67 y ss., 79 y ss.

79 KANT, 1870: I, IV, 28. Tal definición de «imputación» se encuentra sistemáticamente conectada con las correspondientes definiciones de «hecho» y «persona» (23 y ss.). La traducción del término «Urheber» como «autor» no resulta del todo exacta, pudiendo pensarse que sería preferible recurrir al término «agente»; sin embargo, a diferencia de la expresión «el agente de una acción», la expresión «el autor de una acción» logra eludir la redundancia. Acerca de la concepción kantiana de la imputación en la literatura más reciente, vid. Aichele, 2008: 14 y ss.; ByrD y HrUSCHKA, 2010: 290 y ss.; RENZIKOwSKI, 2011: 209 y ss.; STÜBINGER, 2011: 163 y ss.; en detalle SÁNCHEZ-OSTIZ, 2008: 53 y ss.

80 Vid. BYRD y HRUSCHKA, 2010: 290 y ss.

81 Acerca de la fungibilidad de los conceptos de hecho (Tat) y obra (Werk) para designar aquello que es adscrito a un agente tratándose de «acciones positiva o negativamente interesantes», vid. BRENNENSTUHL, 1975: 25 y ss.

82 Vid. HruschKa, 1984: 665 y ss.; HruSCHKA, 1998; HRUSCHKA, 2001: 877 ss; JoERdEN, 1988: 30 y ss.; BIEWALD, 2003: 65 y ss.; SÁNCHEZ-OSTIZ, 2008: 20 y ss.

83 Vid. Aichele, 2008: 16 y ss.; RenZIKOWski, 2011: 210 y ss. Para una revisión crítica de semejante aplicación del postulado de una «causa primera», vid. ya FEINBERG, 1970: 152 y ss., en contra del así llamado «principio de la intervención voluntaria»; al respecto en detalle BRATMAN, 2006: 11 y ss. 
A esto último subyace una interpretación indeterminista del concepto de agencia, cuyos méritos admiten ser puestos en duda si se adopta una concepción compatibilista de la capacidad de autonomía personal en tanto presupuesto de la imputación ${ }^{84}$. Pero aquí sólo interesa una de las implicaciones de semejante concepción indeterminista de la agencia para la articulación del concepto de imputación, a saber: el compromiso con la existencia de una forma específica de causalidad, que sería propia y exclusiva de las relaciones de agencia. En los términos de filosofía analítica de la acción, se trata de la así llamada «causalidad-de-agente» (o «causación inmanente»), entendida como forma de causalidad contrapuesta a la (tradicional) «causalidad-entre-eventos» (o «causación transeúnte») ${ }^{85}$.

El problema es que semejante representación de una específica «causalidad-deagente» resulta difícilmente viable ${ }^{86}$. La noción de causalidad desempeña una función insustituible a la hora de determinar si una determinada acción es susceptible de ser adscrita a una persona. Pues de cuál sea la cadena causal en la que pueda insertarse una acción dependerá cuál sea el espectro de las descripciones verdaderas de esa misma acción. En esto consiste el así llamado «efecto-acordeón» que caracteriza la adscripción de acciones susceptibles de satisfacer descripciones de mayor o menor complejidad causal $^{87}$ : la relación de agencia que se da entre una persona y una acción se conserva a través de las diferentes descripciones verdaderas de esa acción. Así, si una persona A ha jalado el gatillo de un arma de fuego, y el jale del gatillo ha llevado a -en el sentido de que ha condicionado- que una bala salga disparada desde el arma, entonces la acción consistente en disparar el arma de fuego cuenta como una acción de A; y si este mismo disparo del arma ha llevado a que $\mathrm{B}$ muera, por haber sufrido éste el impacto de bala, entonces la acción consistente en matar a $\mathrm{B}$ cuenta como una acción de $\mathrm{A}^{88}$. Mas nada de ello contribuye a responder la pregunta de por qué ya la acción consistente en el jale del gatillo, en tanto «acción primitiva», efectivamente habría de ser adscrita a A. Se trata aquí de una acción primitiva, pues su identificación como tal es relativa a una descripción que no menciona consecuencia causal alguna que sea predicable de esa acción ${ }^{89}$.

El criterio para que semejante acción primitiva en efecto cuente como una acción de A no se deja articular como un criterio causal, desde ya si por «causalidad» se entiende, por el momento, nada más que una «causalidad-entre-eventos» ${ }^{90}$. Pues de lo contrario

${ }^{84}$ Una concepción compatibilista, en este contexto, se distingue por afirmar la compatibilidad del reconocimiento de autonomía personal —en la terminología clásica: de «libertad de voluntad»— con la (eventual) verdad de una tesis determinista. Para una defensa de un argumento compatibilista, vid. MAÑALICH, 2009: 289 y ss., 299 y ss.; MAÑALICH, 2010a: 58 y ss., con ulteriores referencias.

85 Vid. solamente CHISHOLM, 1982: 26 y ss.; Goldman, 1970: 80 y ss.; BISHOP, 1983; coincidentemente MEIXNER, 1994: 481 y ss.

${ }_{86}$ Para la crítica de las tesis favorables a la así llamada «causalidad-de-agente», y desde perspectivas diferentes, vid. por ejemplo THALBERG, 1967; DANTO, 1973: 51 y ss.; DAVIDSON, 2001: 43 y ss., 48 y ss. 52 y ss.; von Wright, 1974: 48 y ss.; Dennett, 1984: 74 y ss.; Mele, 2001: 10 y ss.; SNEDdon, 2006: 97 y ss., 102 y ss. Fundamental al respecto VENDLER, 1984.

87 Fundamental FeINBERG, 1970: 132 y ss.; también DAvidSON, 2001: 53 y ss. Para la comparación de una y otra concepción, vid. BRATMAN, 2006. Para su recepción en la dogmática del derecho penal, vid. KINDHÄUSER, 1989: 50 y ss.; KINDHÄUSER, 2011: 44 y ss.

88 Vid. VendLER, 1984: 378 y ss.

89 Vid. DAVIDSON, 2001: 49 y ss.

90 Fundamental al respecto VendLER, 1984: 374 y ss. 
parece volverse imposible contrarrestar la objeción de un regreso al infinito - a menos que uno estuviera dispuesto a recurrir a la muy oscura noción de «acto mental»—-para explicar en qué podría consistir aquello que la persona A supuestamente tendría que hacer para «causar» una acción (en tal medida: sólo aparentemente) primitiva como la de jalar el gatillo ${ }^{91}$. Precisamente en pos de neutralizar tal objeción, DANTO introdujo la noción de «acción básica», para así identificar aquellas acciones de una persona de las cuales no se dejaría decir que hayan sido causadas a través de alguna otra acción de esa misma persona ${ }^{92}$. Esta formulación dista de ser satisfactoria, tal como lo muestra su aplicación al caso del jale del gatillo. Pues sería al menos anómalo sugerir que al jalar el gatillo del arma, A causó su propia acción de disparar el arma, y así también causó su propia acción letal para B. Por el contrario, parece más satisfactorio afirmar que A ejecutó la acción consistente en matar a $\mathrm{B}$ por la vía de ejecutar la acción consistente en el disparo del arma, y que A ejecutó la acción consistente en el disparo del arma por la vía de ejecutar la acción consistente en el jale del gatillo. Puesto como fórmula general: una acción cuenta como «mediada», si su ejecución tiene lugar a través de la ejecución de alguna otra acción ${ }^{93}$; una acción cuenta como básica, en cambio, si su ejecución no tiene lugar a través de la ejecución de alguna otra acción ${ }^{94}$.

Pero aun así reformulada, la distinción entre una acción básica y una acción mediada parecería llevar a la conclusión de que — para seguir con el ejemplo— al jalar el gatillo y, «por esa vía», disparar el arma y, «por esa vía», producir la muerte de B, A habría ejecutado no una, sino más bien tres acciones, a saber: la acción consistente en jalar el gatillo, la acción consistente en disparar el arma, y la acción consistente en matar a B. Ésta es la conclusión, poco ahorrativa ontológicamente, a la cual tendría que llevar la adopción de una tesis intensionalista (o «de grano fino») para la individuación de acciones ${ }^{95}$. Frente a ello, es posible sin más asumir —en el sentido de una tesis ex-

91 Vid. DAVIDSON, 2001: 52; SNEDDON, 2006: 102. Fundamental para la crítica de la noción de «volición» o «acto mental», en referencia específica a los presupuestos de la atribución de responsabilidad, HART, 1968: 90 y ss.; también KINDHÄUSER, 1980a: 105 y ss.

92 Vid. DANTO, 1963; DANTO, 1965; DANTO, 1973: 28 y ss., 51 y ss., 79 y ss.; DanTO, 1979. Para algunas muestras de la copiosísima bibliografía (en buena medida crítica) suscitada al respecto, vid. STOUTLAND, 1968; Baier, 1971; Martin, 1972; PeArS, 1975; AnNAS, 1978. Para la recepción del problema en la discusión alemana, vid. KINDHÄUSER, 1980b.

93 La terminología procede de DANTO, 1973: 28 y ss., quien observa, empero, que no toda acción nobásica contaría como una acción mediada, puesto que habría casos en que alguien ejecuta una acción no-básica sin ejecutar una acción básica que esté causalmente conectada con aquélla. Tal sería el caso de una acción — compleja, pero no mediada - consistente en la performance de una determinada pieza de baile: las distintas acciones básicas que se corresponden con cada uno de los movimientos que conjuntamente constituyen la realización de la pieza de baile no estarían causalmente conectadas con ésta en tanto acción compleja; antes bien, la conexión en cuestión estaría establecida por las reglas que definen a esa pieza de baile como tal. Nótese que la plausibilidad del argumento en todo caso depende de que la performance de una determinada pieza de baile efectivamente cuente como la ejecución de una acción (compleja), y no, en cambio, como el desarrollo de una actividad (como lo es, paradigmáticamente, bailar). Fundamental al respecto, por referencia a la distinción entre procesos y eventos, VON WRIGHT, 1963a: 41 y ss. Una distinción sólo parcialmente coincidente —a saber: entre actividades y performances en tanto especies del género «acción»—- se encuentra en KENNY, 2003: 120 y ss.

94 Así precisamente STOUTLAND, 1968: 468 y ss., 471 y ss.; KINDHÄUSER, 1980b: 488 y ss.

95 Una concepción intensionalista extrema se distingue por la postulación de la identidad de las propiedades de una acción como criterio de individuación. Así paradigmáticamente GOLDMAN, 1970: 1 y ss., 10 y ss.; vid. también KINDHÄUSER, 2011: 46 y ss. A favor de una concepción intensionalista moderada (o «composicional»), en cambio, vid. VON Wright, 1971: 64 y ss., 67 y ss., 86 y ss., quien entiende que, en la medida en que un determinado «resultado» (por oposición a una «consecuencia») pueda contar como «parte esencial» de una 
tensionalista (o «de grano grueso») — que aquí no cabe diferenciar tres acciones, sino sólo tres descripciones alternativas de una única acción susceptible de ser adscrita a $\mathrm{A}^{96}$. Que las tres descripciones son verdaderas de la misma acción de A es algo que depende de la relación de causalidad en que se encuentran los dos eventos identificados como los respectivos resultados de la acción bajo sus dos últimas descripciones —a saber: el resultado del disparo del arma y el resultado de la muerte de B-, tal como lo sugiere la metáfora del efecto-acordeón ${ }^{97}$. Pues como observa DAVIDSON: «El acordeón, que permanece idéntico a través de su contracción y expansión, es la acción» ${ }^{98}$.

Pero según ya se anticipara, el recurso a la noción de causalidad nada dice acerca de por qué la acción de $\mathrm{A}$, ya bajo su descripción «primitiva» como consistente en el jale del gatillo, en efecto cuenta como una acción de A. Pues como lo sugiere la célebre observación de WiTTGENSTEIN: «¿Qué es lo que queda si del hecho de que yo alce mi brazo extraigo el hecho de que mi brazo se alza?» ${ }^{99}$. El problema no se disipa si uno pretendiera invocar aquí una noción distinta - $\mathrm{y}$ ad hoc- de causalidad, como la noción de «causalidad-de-agente», que en lo que aquí interesa resulta enteramente equivalente al concepto kantiano de causa libera. En la medida en que tal noción de «causalidad-de-agente» no ofrece canon explicativo alguno que contribuya a respon-

acción, tal resultado contará como marca de la falta de identidad entre esa acción y alguna acción cuya identificación no incorpore referencia alguna a ese resultado. Análogamente THOMSON, 1971. Para la correspondiente taxonomía de las posiciones en disputa aquí seguida, vid. MOORE, 1993: 280 y ss.

96 Fundamental Anscombe, 1963: 37 y ss., 45 y ss.; AnsCOMBE, 1979: 219 y ss.; DAVIDSON, 2001: 43 y ss., 128 y ss., 163 y ss.; asimismo SEARLE, 2010: 36 y ss. Sobre el problema vid. también DANTO, 1973: 39 y ss., quien en definitiva se inclina, empero, por una concepción intensionalista (204, nota 14$)$.

${ }_{97}$ Esto tiene importancia para evaluar los méritos del así llamado «argumento de la conexión lógica», cuya invocación en este contexto apunta a que el resultado «intrínseco» de una acción no estaría causalmente conectado con ésta, en la medida en que la conexión entre la acción y «su» resultado tendría el estatus de una relación de necesidad conceptual, lo cual sería incompatible con el carácter lógicamente contingente que habría de exhibir una conexión causal en tanto relación «empírica»; argumento que suele ser invocado en defensa de la tesis de que una acción no podría ser entendida como un evento. Vid. en este sentido VON WRIGHT, 1963a: 39 y ss.; VON WRIGHT, 1971: 64 y ss., 67 y ss.; STOUTLAND, 1968: 470 y ss.; KINDHÄUSER, 1980a: 159 y ss.; KINDHÄUSER, 1980b: 480 y ss.; KINDHÄUSER, 1982: 487 y ss. Pero si, adoptando una tesis extensionalista, se sostiene que es una misma acción la que satisface las diferentes descripciones de menor o mayor complejidad causal vinculadas en el sentido del «efecto-acordeón», cabe concluir que la conexión lógica entre una acción y el correspondiente resultado es relativa a la descripción (causalmente compleja) que incorpora una referencia a la consecuencia (en tal medida) identificada como el resultado de la acción. Sería ciertamente extraño decir que la acción de A consistente en matar a B causó la muerte de B; pero solamente porque esa descripción ya incorpora una referencia al resultado constituido por la muerte de B como consecuencia causal de la acción de A. Vid. VENDLER, 1984: 373 y ss., a propósito de las construcciones verbales «causativas»; y VeNDLER, 1967: 147 y ss., 160 y ss., para un muy refinado análisis de la gramática de los conceptos de «efecto», «resultado» y «consecuencia» (aun cuando concluyendo que el estatus ontológico de un efecto sería el de un evento o proceso, mientras que el estatus ontológico de un resultado o una consecuencia -al igual que el de una causa - sería el de un hecho), quien por lo demás ofrece la siguiente observación para dar cuenta de la relatividad de la distinción entre el resultado y la(s) consecuencia(s) de una acción cualquiera: «el hombre afortunado obtiene resultados; el desafortunado obtiene consecuencias». Valga la precisión de que la versión más célebre del argumento de la conexión lógica se corresponde con su invocación, mutatis mutandis, en defensa de la tesis según la cual la razón por la cual alguien ejecuta una acción no podría contar como causa de esa misma acción. Fundamental para la impugnación de la validez del argumento de la conexión lógica en este último contexto, MACKIE, 1980: 270 y ss., 287 y ss.

${ }^{98}$ DAVIDSON, 2001: 58.

99 Wittgenstein, 1984b: $\$ 621$. Vid. Vendler, 1984: 372 y ss., enfatizando la necesidad de diferenciar el evento designado por la descripción «el alzarse el brazo» (the rising of the arm), en la cual «alzar» (to rise) es usado como verbo intransitivo, del evento designado por la descripción «el alzar el brazo» (the raising of the arm), en la cual «alzar» es usado como verbo transitivo. 
der la pregunta acerca de las condiciones bajo las cuales un evento cualquiera puede contar como la acción de una persona, «parece no haber diferencia entre decir que alguien causó una acción primitiva y decir que él fue el agente» ${ }^{100}$.

La inviabilidad de un criterio causal para la atribución de agencia lleva a DAVIDSON a favorecer, en cambio, un criterio intencional: «Una persona es el agente de un evento si y sólo si hay una descripción de lo que hizo que vuelve verdadera una oración que dice que lo hizo intencionalmente» ${ }^{101}$. Aquí no interesa indagar en los méritos específicos de esta tesis ${ }^{102}$, sino reparar en el carácter irreductiblemente adscriptivo del reconocimiento de agencia que se sigue de la aplicación de semejante criterio. Pues el reconocimiento de la intención con la cual una persona hace algo sólo es posible en la forma de una atribución de esa intención, lo cual quiere decir: en la forma de una atribución de un compromiso práctico ${ }^{103}$.

\section{LA PERFORMATIVIDAD DE LA IMPUTACIÓN}

Lo anterior sugiere la conveniencia de purgar la definición kantiana del concepto de imputación de su compromiso parcial con una aproximación ontológica, para así radicalizar su compromiso con una aproximación pragmatista. Así tomada, la definición ofrece una clave ulterior para la clarificación de la noción de imputación. Pues en tanto instancia de juicio práctico, imputar algo a alguien consiste en efectuar un acto de habla que exhibe una fuerza pragmática distintiva. Pero sería un error identificar esta fuerza pragmática o «ilocutiva» con la habilitación (formal o informal) a la materialización de una determinada consecuencia favorable o desfavorable para el sujeto pasivo de la imputación, lo cual supondría, en los términos de KANT, confundir el modo genérico de la imputatio («a secas») con el modo específico de la imputatio judiciaria. Precisamente aquí radica el defecto del análisis de la lógica de las adscripciones de acciones que MACKIE elabora en el marco de su revisión crítica del adscriptivismo hartiano.

MACKIE sostiene que el así llamado «uso adscriptivo del lenguaje» no consistiría más que en la combinación de un componente descriptivo y un componente prescriptivo ${ }^{104}$. Su análisis se centra en uno de los ejemplos a los cuales HART prestara mayor atención, en paralelo al caso de la adscripción de una acción, en la elaboración de su argumento a favor del adscriptivismo, a saber: el caso en que se afirma la satisfacción de las condiciones de existencia de un contrato ${ }^{105}$. Según MACKIE, cuando se sostiene que entre $A$ y $B$ existe un contrato puede estar simplemente constatándose que se satis-

100 DAVIDSON, 2001: 52.

101 Ibid., 46. El criterio de la intencionalidad, así entendido, resulta ser intensional (= relativo-a-la-descripción), en la medida en que el reconocimiento del carácter intencional de una acción es relativo a alguna de sus múltiples descripciones verdaderas, lo cual no obsta a que la expresión (operativa) del mismo criterio sea perfectamente extensional: la acción identificada como tal bajo aquella descripción que la convierte en una acción intencional de la persona P cuenta como acción de P bajo todas y cada una de sus descripciones verdaderas, con independencia de si bajo una o más de éstas la acción ya no cuenta como intencional.

102 En este sentido MAÑALICH, 2009: 279 y ss.; MAÑALICH, 2010a.

103 Fundamental al respecto BRANDOM, 1994: 243 y ss., 253 y ss.

104 MACKIE, 1985: 32 y ss.

105 Vid. HART, 1949: 174 y ss. 
facen las condiciones de las cuales depende que A y B hayan efectivamente celebrado un contrato (válido); pero también, y ante todo si quien lo sostiene es un juez (en tanto juez), puede estar dándose una instrucción a las partes ( $\mathrm{A}$ y B), así como eventualmente a terceros, acerca de qué han de hacer o no hacer ${ }^{106}$.

$\mathrm{El}$ argumento dista de ser concluyente. Ciertamente, no cabe poner en duda que el hecho de que entre A y B haya sido celebrado un contrato hace posible concluir, ceteris paribus, que de ello se siguen obligaciones para $\mathrm{A} y(\mathrm{o}) \mathrm{B}{ }^{107}$. Pero esto no es algo que dependa de la fuerza pragmática de la afirmación de que el contrato en cuestión ha sido celebrado, sino más bien del contenido proposicional de esa afirmación. Pues trivialmente, lo que cuenta como un contrato queda (funcionalmente) definido por su eficacia generadora de obligaciones para quienes lo celebran. Tal como ya se ha sostenido, nada parecido es necesariamente predicable de la emisión de una oración del tipo «A ha ejecutado la acción $\phi »$. Esto no basta, sin embargo, para descartar que la fuerza pragmática característica de aquellos actos de habla que cuentan como instancias de uso adscriptivo del lenguaje sea en efecto una fuerza híbrida, susceptible de ser descompuesta en fuerzas ilocutivas más básicas. La pregunta es, más bien, cuáles pudieran ser esas fuerzas ilocutivas, una vez descartado —en contra del argumento de MACKIE- el componente supuestamente prescriptivo.

La clave para responder esta pregunta aparece en la siguiente observación de MACKIE, relativa a lo que sucede cuando un juez, en las circunstancias contextualmente apropiadas, afirma que A y B están vinculados por un contrato: el juez «está al mismo tiempo enunciando algo y convirtiendo su enunciado en verdadero» ${ }^{108}$. El punto se deja explicar como sigue. Es correcto reconocer en el uso adscriptivo del lenguaje - por ejemplo, en lo que hace un hablante cuando adscribe una determinada acción a una persona- una combinación de dos fuerzas ilocutivas susceptibles de ser analíticamente diferenciadas; la primera de ellas consiste en lo que MACKIE identifica como la enunciación de algo, esto es, en la fuerza pragmática característica de un «acto de habla asertivo»; la segunda, en lo que MACKIE identifica como la conversión de lo enunciado en verdadero, lo cual se ajusta muy precisamente a la fuerza pragmática característica de un «acto de habla declarativo» ${ }^{109}$.

Bajo la taxonomía de SEARLE, una aserción consiste en la afirmación de la verdad de una proposición; de ahí que semejante acto de habla exhiba una dirección unilateral de ajuste entre las palabras y el mundo (word-to-world direction of fit), en términos tales que el «punto ilocutivo» de una aserción consistiría en que lo dicho se ajuste a (cómo son) los hechos ${ }^{110}$. En cambio, una declaración consiste en una determinada transformación —característicamente: institucional- del mundo, que determina que una proposición se convierta eo ipso en verdadera; de ahí que semejante acto de habla exhiba una relación de ajuste bidireccional entre las palabras —en rigor: lo dicho- $-\mathrm{y}$

106 MACKIE, 1985: 33.

107 Que también puedan seguirse obligaciones para (un tercero) C, en el sentido de una Drittwirkung, es algo en lo cual no es necesario ni pertinente entrar aquí.

108 MACKIE, 1985: 33.

109 Vid. SEARLE, 1979: 12 y ss. Para una relativización de la pretensión de exhaustividad de la clasificación de los tipos de actos ilocutivos propuesta por SEARLE, vid. MAÑALICH, 2010b: 127 y ss., 135 y ss.

$110 \mathrm{Al}$ respecto SEARLE, 1979: 3 y ss. 
el mundo, en términos tales que su realización exitosa garantizaría que el contenido proposicional de la declaración se corresponda con (cómo son) los hechos ${ }^{111}$.

Notablemente, SEARLE advierte que habría que reconocer una subclase de actos de habla declarativos, cuyos miembros se distinguirían por quedar asimismo incluidos en la clase de los actos asertivos ${ }^{112}$. Uno de sus ejemplos es la declaración de culpabilidad pronunciada por un tribunal que ejerce jurisdicción en lo penal. Pues una persona que es declarada culpable frente a un cargo por un presunto hecho punible ciertamente ve modificado su estatus jurídico como resultado de la declaración, sin que ello alcance a volver impertinente la pregunta de si efectivamente esa persona es autora de aquello que se le imputa. Dicho en otros términos: la relación de ajuste bidireccional entre lo que se dice — «las palabras»-y lo que es el caso — «el mundo»-, que queda asegurada por la sola declaración, deja abierta una dimensión diferente del mismo acto de habla en que la correspondiente relación de ajuste es puramente unidireccional, en el sentido de que el hecho de que la persona $\mathrm{P}$ (efectivamente) sea culpable de haber ejecutado la acción $\phi$ - por oposición a que solamente haya sido declarada culpable de ejecutar la acción $\phi$ - depende de que sea verdad que $\mathrm{P}$ ha ejecutado la acción $\phi^{113}$.

Para hacer referencia a este subconjunto de actos de habla cuya fuerza ilocutiva sería simultáneamente declarativa y asertiva, SEARLE propone hablar de «declaraciones asertivas» ${ }^{114}$. Y lo ya sostenido muestra que a esta subclase pertenecen aquellos actos de habla distintivamente adscriptivos, a través de los cuales un hablante imputa algo a alguien. Lo crucial ahora es distinguir lo que está en juego en relación con cada uno de los dos componentes de la fuerza ilocutiva de una imputación, así entendida. El componente asertivo (o «constatativo») determina que una imputación no sea reducible a la declaración de que alguien ha hecho o no ha hecho algo, lo cual determina, a su vez, la irreductible posibilidad de que una imputación sea incorrecta, en la medida en que sea falsa la proposición cuya verdad es afirmada por el sujeto activo de la imputación. De ahí, por lo demás, que un hablante pueda menoscabar ilegítimamente —en la terminología de BRANDOM: sin título - el honor de otra persona, en el sentido de una calumnia o una injuria, a través de una imputación falsa ${ }^{115}$, esto es: a través del registro de un cargo inmerecido en su cuenta. El análisis del componente declarativo, empero, es lo que interesa para cerrar esta indagación. Pues este componente determina la fuerza propiamente transformativa que distingue a una imputación. Se trata de la

111 SEARLE, 1979: 16 y ss.; SEARLE, 2010: 11 y ss.

112 SEARLE, 1979: 19 y ss.

113 Así se deja entender la distinción entre lo que MEIXNER propone entender como un concepto objetivo y un concepto subjetivo de imputación: en sentido objetivo, se trataría del uso del predicado (biposicional) « $x$ ha de ser imputado a $y »$, lo cual expresaría que algo ha de imputarse —en el sentido de que es imputable- a alguien; en sentido subjetivo, en cambio, se trataría del uso del predicado (biposicional) «x es imputado a $y »$, que expresa que a alguien («simplemente») se imputa algo. Vid. MEIXNER, 1994: 479 y ss. Que efectivamente tenga lugar una imputación («en sentido subjetivo») no garantiza, entonces, que haya de tener lugar una imputación («en sentido objetivo»); sólo la satisfacción conjunta de las condiciones para una y otra modalidad de uso, en consecuencia, haría posible hablar de una imputación «correcta».

114 SEARLE, 1979: 20.

115 Vid. MAÑALICH, 2005: 210 y ss., para un desarrollo de la tesis de la «imputación informal» para la caracterización de la específica ilicitud de la calumnia y (de ciertas variantes de) la injuria, aunque enfatizando unilateralmente el componente asertivo de la fuerza pragmática característica de una imputación. 
transformación de la identidad del agente a quien se imputa haber hecho (o no haber hecho) algo ${ }^{116}$. En la formulación de G. JAKOBS,

[e]n la determinación del concepto de acción no se trata solamente de imputar a un sujeto su acción, sino que con el establecimiento del concepto de acción se determina asimismo qué es un sujeto y qué es su acción ${ }^{117}$.

Aquí cabe notar el rigor terminológico de la recepción de las categorías de la filosofía hegeliana del derecho: los conceptos de acción y sujeto, en tanto categorías de la esfera de la moralidad, constituyen el par correlativo a los conceptos de becho y persona, en tanto categorías de la esfera del derecho abstracto ${ }^{118}$ (lo cual enseña que el uso que HEGEL hace de la distinción entre «hecho» y «acción» es precisamente el inverso del que se expresa en la definición kantiana del concepto de imputación ${ }^{119}$ ). En palabras de QUANTE:

Si lo realizado por mí [mein Tun] es descrito como un hecho [Tat], entonces se da por supuesto que soy un sujeto; pero si es descrito como una acción [Handlung], entonces soy reconocido como un sujeto determinado, puesto que mi perspectiva es considerada. La específica descripción de lo realizado como una acción muestra quién uno es ${ }^{120}$.

Pero entonces se vuelve necesario advertir, para quedarnos con HEGEL, que «lo que un sujeto es» no es más que «la serie de sus acciones» ${ }^{121}$, en el sentido de que su («verdadera») identidad recién se muestra —en la jerga de la imputación- en su total y definitivo estado de cuenta. Así, lo que está en juego en la adscripción de una acción es, en último término, quién es el agente en cuya cuenta ella es registrada ${ }^{122}$. Por eso, si se trata de la adscripción de una acción meritoria, el premio radica ya en la (adscripción de la) acción misma; y si se trata de la adscripción de una acción demeritoria, el castigo radica ya en la (adscripción de la) acción misma. En uno y otro caso, el premio y

116 Lo cual se explica por la circunstancia de que una imputación exhibe el estatus de un juicio práctico, y no teórico: la adscripción de un evento como acción a una persona redefine tanto aquello que se imputa como a quien ello se imputa. Así ya KINDHÄUSER, 1984: 5 y ss., 16 y ss. El carácter «semánticamente transformativo» que distingue a una imputación es resaltado por VAN ALPHEN, 1993: 174 y ss., aunque circunscrito al objeto de la respectiva imputación.

117 JAKOBS, 1991: 6/20.

118 Vid. HegeL, 1821: $\$ \$ 96,105,113,117$ y ss. Fundamental para la interpretación aquí favorecida, QuANTE, 1993: 39 y ss., 134 y ss.; QuANTE, 2011: 196 y ss., 207 y ss.

119 Vid. supra, nota 79.

120 QUANTE, 1993: 54. Aunque la traducción de la expresión «mein Tun» como «lo realizado por mí» resulta un tanto artificial, sirve para evitar la redundancia que se seguiría de traducirla, más naturalmente, como «lo hecho por mí» («Si lo hecho por mí es descrito como un hecho...»). Nótese, por lo demás, que esta lectura de HEGEL supone favorecer — como lo advierte QuANTE, 1993: 141 y ss., 160 y ss.— una tesis extensionalista o «de grano grueso» para la individuación del evento que puede contar como el «hecho» (Tat) de una persona, en el sentido de que el «hecho» cuenta como tal bajo todas y cada una de sus descripciones alternativas (verdaderas), siempre que al menos bajo una de éstas el mismo resulte intencional; sólo la especificación del «hecho» como «acción» (Handlung) de esa persona es relativa a aquella descripción bajo la cual el «hecho» resulta intencional. Vid. supra, notas 95-97 y 101, así como la correspondiente sección del texto principal. En tal medida, es a lo menos equívoco suponer — tal como, aunque en otro contexto, lo sugiere QUANTE, 2011: 250, nota 29- que a HEGEL pudiese atribuirse una «ontología de eventos de grano fino» à la GOLDMAN. Pues al menos en lo que aquí interesa, la intensionalidad de la especificación de la «acción» no se comunica a la individuación del «hecho» correspondiente.

121 Hegel, 1821: $\$ 124$. Vid. al respecto Larenz, 1927: 66 y ss.; también Pippin, 2008: 165 y ss., 167 y ss. Contextualizando la observación de HEGEL como manifestación de un «adscriptivismo cognitivista», QUANTE, 2011: 224 y ss.

122 Fundamental al respecto DAN-COHEN, 2002: 209 y ss. 
el castigo —en sentido ético à la WITTGENSTEIN- se identifican con el reconocimiento declarativo del estatus del agente como el autor de la acción en cuestión. Lo cual significa, en terminología kantiana, que semejante premio o castigo declarativo es inmanente a la sola imputatio disjudicatoria.

Esto vuelve comprensible la insistencia de H. ARENDT en cuanto a la sabiduría contenida en el dictum socrático según el cual sería preferible que otro cometa una injusticia en mi persona a que yo cometa una injusticia en la persona de otro; o puesto más drásticamente: que otro me mate injustamente a que yo lo mate injustamente ${ }^{123}$. Pues en este último caso, mi condena consistirá en quedar forzado a compartir mi vida con un asesino.

\section{BIBLIOGRAFÍA}

AiCHeLE, A., 2008: «Persona physica und persona moralis: Die Zurechnungsfähigkeit juristischer Personen nach Kant», Jabrbuch für Recht und Ethik, 16: 3-23.

AnNAS, J., 1978: «How Basic Are Basic Actions?», Proceedings of the Aristotelian Society, 78: 195-213.

Anscombe, G. E. M., 1959: An Introduction to Wittgenstein's Tractatus, New York: Harper Torchbooks.

- 1963: Intention, 2. ${ }^{a}$ ed., Cambridge (Mass.) y London: Harvard University Press.

- 1979: «Under a Description», Nô̂s, 13: 219-233.

ARENDT, H., 2003: Responsibility and Judgment, New York: Schocken Books.

Austin, J. L., 1962: How to Do Things with Words, 2. ${ }^{a}$ ed., Cambridge (Mass.): Harvard University Press.

- 1970: Philosophical Papers, 2. ${ }^{a}$ ed., Oxford: Clarendon Press.

BAIER, A., 1971: «The Search for Basic Actions», American Philosophical Quarterly, 8: 161-70.

BERNER, A. F., 1843: Grundlinien der criminalistischen Imputationslehre, Fráncfort del Meno: Verlag Sauer \& Auvermann (reimp.: 1968).

BIEWALD, G., 2003: Regelgemäßes Verbalten und Verantwortlichkeit, Berlin: Duncker \& Humblot. BIRNBACHER, D., 1995: Tun und Unterlassen, Stútgart: Reclam.

Bishop, J., 1983: «Agent-Causation», Mind, 92: 61-79.

BRANDOM, R., 1994: Making it Explicit, Cambridge (Mass.): Harvard University Press.

Bratman, M., 2006: «What is the Accordion Effect?», The Journal of Ethics, 10:5-19.

BRENNENSTUHL, W., 1975: Handlungstheorie und Handlungslogik, Kronberg: Scriptor Verlag.

ByRD, S., y HruschKa, J., 2010: Kant's Doctrine of Right, Cambridge: Cambridge University Press.

Cacciatore, G., 2004: «Der Begriff der Zurechnung in der Phase der italienischen Rechtsphilosophie», en M. KAUfMANN y J. RENZIKOwSKI, Zurechnung als Operationalisierung von Verantwortung, Fráncfort del Meno: Peter Lang, 29-45.

Chisholm, R., 1982: «Human Action and the Self», en G. Watson, Free Will, Oxford y New York: Oxford University Press, 24-35.

CruZ, M., 1990: «Origen y desembocadura de la acción: el sujeto inevitable», Revista Hispanoamericana de Filosofía, 23: 97-120.

${ }^{123}$ ARENDT, 2003: 49 y ss., 82 y ss., 90 y ss. 
Dan-Cohen, M., 2002: Harmful Thoughts, Princeton y Oxford: Princeton University Press.

DANIELS, C., 1970: «Hare on the Meaning of "Good"», Mind, 79(313): 139-141.

DANTO, A., 1963: «What We Can Do», Journal of Philosophy, 60: 435-445

— 1965: «Basic Actions», American Philosophical Quarterly, 2: 141-148.

- 1973: Analytical Philsophy of Action, Cambridge: Cambridge University Press.

- 1979: «Basic Actions and Basic Concepts», The Review of Metaphysics, 32: 471-85.

Davidson, D., 2001: Essays on Actions and Events, 2. ${ }^{a}$ ed., Oxford: Oxford University Press.

- 2004: Problems of Rationality, Oxford: Oxford University Press.

- 2005: Truth, Language, and History, Oxford: Oxford University Press.

DennetT, D., 1984: Elbow Room, Oxford: Clarendon Press.

DuARTE, L., 2007: «Ascriptivism and the Criminal Law», Archiv für Rechts- und Sozialpbilosophie, Beiheft 106 (Legal Positivism and Conceptual Analysis): 259-263.

Feinberg, J., 1970: Doing E Deserving, Princeton (N. J.): Princeton University Press.

GEACH, P., 1956: «Good and Evil», Analysis, 17: 33-42.

- 1960: «Adscriptivism», The Philosophical Review, 69: 221-25.

Goldman, A., 1970: A Theory of Human Action, Engelwood Cliffs (N. J.): Prentice-Hall.

GREEN, S., 2004: «Cheating», Law E Philosophy, 23: 137-85.

GÜNTHER, K, 2005: Schuld und kommunikative Freibeit, Fráncfort del Meno: Vittorio Klostermann.

Habermas, J., 1988: Nachmetaphysisches Denken, Fráncfort del Meno: Suhrkamp.

HaRDwig, W., 1957: Die Zurechnung. Ein Zentralproblem des Strafrechts, Hamburgo: Cram, de Gruyter \& Co.

Hare, R. M., 1961: The Language of Morals, Oxford: Oxford University Press.

— 1970: «Meaning and Speech Acts», The Philosophical Review, 79: 3-24.

Hart, H. L. A., 1949: «The Ascription of Responsibility and Rights», Proceedings of the Aristotelian Society, 49: 171-94.

- 1968: Punishment and Responsibility, Oxford: Clarendon Press.

Hegel, G. W. F., 1821: Grundlinien der Philosophie des Rechts, Léipzig: Felix Meiner (reimp. 1911).

HRuschKA, J., 1976: Strukturen der Zurechnung, Berlin y New York: Walter de Guyter.

— 1984: «Ordentliche und außerordentliche Zurechnung bei Pufendorf», Zeitschrift für die gesamte Strafrechtswissenschaft, 96: 661-702.

- 1986: «Imputation», Brigham Young University Law Review, 669-710.

- 1988a: Strafrecht nach logisch-analytischer Methode, 2. ed., Berlin: Walter de Gruyter.

— 1998b: «Regreßverbot, Anstiftungsbegriff, und die Konsequenzen», Zeitschrift für die gesamte Strafrechtswissenschaft, 110: 581-610.

— 2001: «Bestrafung des Täters trotz Rechtfertigung der Tat?», Zeitschrift für die gesamte Strafrechtswissenschaft, 113: 870-84.

- 2004: «Zurechnung seit Pufendorf. Insbesondere die Unterscheidungen des 18. Jahrhunderts», en M. KAUfMANN y J. RENZIKOWSKI, Zurechnung als Operationalisierung von Verantwortung, Fráncfort del Meno: Peter Lang, 17-27.

- 2005: Imputación y derecho penal, Navarra; Thomson/Aranzadi.

JAKOBS, G., 1991: Strafrecht Allgemeiner Teil, 2. ${ }^{a}$ ed., Berlin: Walter de Gruyter.

JOERDEN, J., 1988: Strukturen des strafrechtlichen Verantwortlichkeitsbegriffs: Relationen und ibre Verkettungen, Berlin: Duncker \& Humblot.

KANT, I., 1797: Metaphysik der Sitten, Léipzig: Verlag der Dürr'schen Buchhandlung (ed. de 1870). 
KelLy, J., 1995: «Wittgenstein, the Self, and Ethics», The Review of Metaphysics, 48: 567-90.

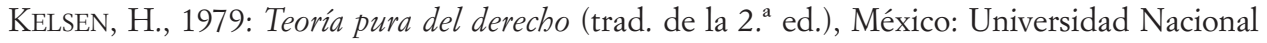
Autónoma de México.

Kenny, A., 2003: Action, Emotion and Will, 2. ${ }^{a}$ ed., London y New York: Routledge.

KindHÄUSER, U., 1980a: Intentionale Handlung, Berlin: Duncker \& Humblot.

— 1980b: «Basis-Handlungen», Rechtstheorie, 11: 479-95.

- 1982: «Kausalanalyse und Handlungszuschreibung», Goltdammer's Archiv für Strafrecht, 477-498.

- 1984: «Der Vorsatz als Zurechnungskriterium», Zeitschrift für die gesamte Strafrechtswissenschaft, 96: 1-35.

- 1989: Gefährdung als Straftat, Fráncfort del Meno: Vittorio Klostermann.

— 2011: «Zum strafrechtlichen Handlungsbegriff», en H.-U. PAEFFGEN et al., Strafrechtswissenschaft als Analyse und Konstruktion. Festschrift für Ingeborg Puppe zum 70 Geburtstag, Berlin: Duncker \& Humblot, 39-63.

KORIATH, H., 1994: Grundlagen strafrechtlicher Zurechnung, Berlin: Duncker \& Humblot.

KRÄMER, S., 2001: Sprache, Sprechakt, Kommunikation, Fráncfort del Meno: Suhrkamp.

Kuhlen, L., 1978: Die Objektivität von Rechtsnormen, Fráncfort del Meno: Peter Lang.

Lance, M., y White, W. H., 2007: «Stereoscopic Vision: Persons, Freedom, and Two Spaces of Material Inference», Philosophers' Imprint, 7(4): 1-21.

LARENZ, K., 1927: Hegels Zurechnungslebre, Aalen: Scientia Verlag, Aalen (reimp. de 1970).

Lour, R., 1995: «Hart's Critics on Defeasible Concepts and Ascriptivism», Proceedings of the 5 th International Conference on Artificial Inteligence and Law, New York, 21-30.

MackIE, J. L., 1980: The Cemment of the Universe, Oxford: Clarendon Press.

- 1985: Persons and Values. Selected Papers II, Oxford: Clarendon Press.

MAÑAliCH, J. P., 2005: «¿Comisión de delitos mediante la imputación de delitos? Los delitos contra el honor bajo la teoría de los actos de habla», Revista Peruana de Doctrina y Jurisprudencia Penales, 6: 193-242.

- 2009: Nötigung und Verantwortung, Baden-Baden: Nomos.

- 2010a: «Determinism, Free Will and Criminal Responsibility», Archiv für Rechts- und Sozialphilosophie, Beiheft 120 (Free Will in Criminal Law and Procedure), 49-61.

- 2010b: «¿Reglas del entendimiento? Acerca de la "juridificación” de la comunicación en la pragmática universal de Jürgen Habermas», Estudios Públicos, 119: 121-49.

- 2010c: «Norma e imputación como categorías del hecho punible», Revista de Estudios de la Justicia, 12: 169-90.

Martin, J., 1972: «Basic Actions and Simple Actions», American Philosophical Quaerterly, 9: 59-68.

McGinn, M., 2001: «Saying and Showing and the Continuity of Wittgenstein's Thought», The Harvard Review of Philosophy, 9: 24-36.

MeIXNER, U., 1994: «Eine Explikation des Begriffs der Zurechnung», Jabrbuch für Recht und Ethik, 2: 479-503.

Mele, A., 2001: Autonomous Agents, New York: Oxford University Press.

Moore, M., 1993: Act and Crime, Oxford: Oxford University Press.

- 1997: Placing Blame, Oxford: Oxford University Press.

Neumann, U., 1985: Zurechnung und „Vorverschulden“, Berlin: Duncker \& Humblot.

PeARS, D., 1975: «The Appropiate Causation of Intentional Basic Actions», Crítica: Revista Hispanoamericana de Filosofía, 7: 39-72. 
PIPPIN, R., 2008: Hegel's Practical Philosophy, Cambridge: Cambridge University Press.

Pitcher, G., 1960: «Hart on Action and Responsibility», The Philosophical Review, 69: 226-35.

Quante, M., 1993: Hegels Begriff der Handlung, Stútgart y Bad Constant: Frommann-Holzboog.

- 2011: Die Wirklichkeit des Geistes, Fráncfort del Meno: Suhrkamp.

Quine, W. V. O., 1960: Word and Object, Cambridge (Mass.): MIT Press.

RADBRUCH, G., 1967: Der Handlungsbegriff in seiner Bedeutung für das Strafrechtssystem, en A. KAUfamnN (ed.), Darmstad: Wissenschaftliche Buchgesellschaft.

ReNZIKOwsKi, J., 2011: «Ist psychische Kausalität dem Begriff nach möglich?», en H.-U. PAEFFGEN et al., Strafrechtswissenschaft als Analyse und Konstruktion. Festschrift für Ingeborg Puppe zum 70 Geburtstag, Berlin: Duncker \& Humblot, 201-216.

RHEEs, R., 1965: «Some Developments in Wittgenstein's View of Ethics», The Philosophical Review, 74: 17-26.

Robinson, P., 1984: «Imputed Criminal Liability», The Yale Law Journal, 93: 609-76.

SÁnCHEZ-Ostiz, P., 2008: Imputación y teoría del delito, Montevideo y Buenos Aires: BdF.

SCHULTE, J., 1989: Wittgenstein. Eine Einführung, Stútgart: Reclam.

SeArle, J., 1969: Speech Acts, Cambridge: Cambridge University Press.

- 1979: Expression and Meaning, Cambridge: Cambridge University Press.

- 2010: Making the Social World, Oxford y New York: Oxford University Press.

SEELman, K., 2004: «Ebenen der Zurechnung bei Hegel», en M. KAUfMAnN y J. RENZIKOwSKI, Zurechnung als Operationalisierung von Verantwortung, Fráncfort del Meno: Peter Lang, 85-92.

SNEDDOn, A., 2006: Action and Responsibility, Dordrecht: Springer.

Stoutland, F., 1968: «Basic Actions and Causality», The Journal of Philosophy, 65: 467-475.

STRAwSON, P. F., 1964: Individuals, London y New York: Routledge.

STÜBINGER, S., 2011: «Von der alten Imputationen-Lehre zum klassischen Verbrechensbegriff Ein Beitrag zur Geschichte des strafrechtlichen Zurechnungsbegriffs», Rechtswissenschaft, 2: 154-76.

Thalberg, I., 1967: «Do We Cause Our Own Actions?», Analysis, 27: 196-201.

Thomson, J. J., 1971: «The Time of a Killing», The Journal of Philosophy, 68: 115-32.

TugendHAT, E., 1976: Vorlesungen zur Einführung in die sprachanalytische Philosophie, Fráncfort del Meno: Suhrkamp.

- 1992: Philosophische Aufsätze, Fráncfort del Meno: Suhrkamp.

Uschanov, T. P., 2002: «Ernest Gellner's criticisms of Wittgenstein and of ordinary language Philosophy», en G. Kitching y N. PLeasants, Marx and Wittgenstein, London y New York: Routledge, 23-46.

VAN AlPHEN, E., 1993: «Kelsen and Hruschka: Concepts of Imputation», International Journal for the Semiotics of Law, VI(17): 163-78.

VAn DER Pfordten, D., 1993: Deskription, Evaluation, Präskription, Berlin: Duncker \& Humblot. VendleR, Z., 1967: Linguistics in Philosophy, Ithaca y London: Cornell University Press.

— 1984: «Agency and Causation», Midwest Studies in Philosophy, 9: 371-84.

Vogel, J., 1993: Norm und Pflicht bei den unechten Unterlassungsdelikten, Berlin: Duncker \& Humblot.

VON BubNOFF, E., 1966: Die Entwicklung des strafrechtlichen Handlungsbegriffes von Feuerbach bis Liszt unter besonderer Berücksichtigung der Hegelschule, Heidelberg: Carl Winter, Universitätsverlag. 
Von Wright, G. H., 1963 a: Norm and Action, London: Routledge \& Kegan Paul.

- 1963b: The Varieties of Goodnes, London: Routledge \& Kegan Paul.

- 1971: Explanation and Undersanding, London: Routledge \& Kegan Paul.

- 1974: Causality and Determinism, New York y London: Columbia University Press.

WALKER, J., 1968: «Wittgenstein's Earlier Ethics», American Philosophical Quarterly, 5: 219-32.

Wiggins, D., 2004: «Wittgenstein on Ethics and the Riddle of Life», Philosophy, 79: 363-91.

WitTgenstein, L., 1984a: Tractatus Logico-Philosophicus, Werksaufgabe 1, Fráncfort del Meno: Suhrkamp.

- 1984b: Philosophische Untersuchungen, Werksaufgabe 1, Fráncfort del Meno: Suhrkamp.

WÜFERL, C., 2012: Freibeit als Grundlage der Schuld, Fráncfort del Meno: Peter Lang.

ZACZYK, R., 2007: «Das Subjekt der objektiven Zurechnung und die Lehre von Günther Jakobs», M. PAWLIK y R. ZACZYK, Festschrift für Günther Jakobs, Colonia: Carl Heymanns, 785-799. 